\title{
Applications of Ionic Liquids in Electrochemical Sensors and Biosensors
}

\author{
Virendra V. Singh, ${ }^{1}$ Anil K. Nigam, ${ }^{1}$ Anirudh Batra, ${ }^{2}$ Mannan Boopathi, ${ }^{1}$ \\ Beer Singh, ${ }^{1}$ and Rajagopalan Vijayaraghavan'
}

${ }^{1}$ Defence Research and Development Establishment, DRDO, Gwalior 474 002, India

${ }^{2}$ Amity University, Noida 201303, India

Correspondence should be addressed to Mannan Boopathi, boopathi@drde.drdo.in

Received 10 August 2011; Accepted 14 November 2011

Academic Editor: Sherif Zein El Abedin

Copyright ( $) 2012$ Virendra V. Singh et al. This is an open access article distributed under the Creative Commons Attribution License, which permits unrestricted use, distribution, and reproduction in any medium, provided the original work is properly cited.

\begin{abstract}
Ionic liquids (ILs) are salt that exist in the liquid phase at and around $298 \mathrm{~K}$ and are comprised of a bulky, asymmetric organic cation and the anion usually inorganic ion but some ILs also with organic anion. ILs have attracted much attention as a replacement for traditional organic solvents as they possess many attractive properties. Among these properties, intrinsic ion conductivity, low volatility, high chemical and thermal stability, low combustibility, and wide electrochemical windows are few. Due to negligible or nonzero volatility of these solvents, they are considered "greener" for the environment as they do not evaporate like volatile organic compounds (VOCs). ILs have been widely used in electrodeposition, electrosynthesis, electrocatalysis, electrochemical capacitor, lubricants, plasticizers, solvent, lithium batteries, solvents to manufacture nanomaterials, extraction, gas absorption agents, and so forth. Besides a brief discussion of the introduction, history, and properties of ILs the major purpose of this review paper is to provide an overview on the advantages of ILs for the synthesis of conducting polymer and nanoparticle when compared to conventional media and also to focus on the electrochemical sensors and biosensors based on IL/composite modified macrodisk electrodes. Subsequently, recent developments and major strategies for enhancing sensing performance are discussed.
\end{abstract}

\section{Introduction}

ILs are a class of materials which have attracted many scientists as holding a great promise for green chemistry applications [1-3]. Paul Walden gave a definition to ILs that is still acknowledged today [4]. They are "materials composed of cations and anions, those melt around $100^{\circ} \mathrm{C}$ or below as an arbitrary temperature limit." This definition identifies the difference from molten salts that have also been known for a long time and are inorganic salts with high melting temperatures [5]. A typical IL has a bulky organic cation (e.g., $\mathrm{N}$-alkylpyridinium, N-N'-dialkylimidazolium) that is weakly coordinated to an organic or inorganic anion, such as $\mathrm{BF}_{4}^{-}, \mathrm{Cl}^{-}, \mathrm{I}^{-}, \mathrm{CF}_{3} \mathrm{SO}_{3}{ }^{-}$, and $\mathrm{AlCl}_{4}{ }^{-}$. The big difference in the size of a bulky cation and a small anion does not allow packing of lattice, which happens in many inorganic salts; instead, the ions are disorganized. This results in that some of these salts remain liquid at the room temperature [2]. ILs are liquid electrolytes composed entirely of ions. Due to the high ionic conductivity, nonvolatility, low vapor pressure, thermal stability, hydrophobicity, and wide electrochemical window that ionic liquids possess, these compounds have become a novel solution to problems encountered with organic solvents and these molecules are a prospective solution to the limitations encountered in electrochemical systems [6, 7]. This new chemical group can reduce the use of hazardous and polluting organic solvents due to their unique characteristics as well as taking part in various new syntheses. Due to these unique properties, ILs have been widely used in different field of applications (Figure 1). These physical properties can be varied by selecting different combinations of ions $[8,9]$. Since the electrochemical window of the pure ILs depends on the electrochemical stability of the cation and/or anion, understanding the ion behavior at the electrode surface leads to improvement and implementation of the IL to the desired 


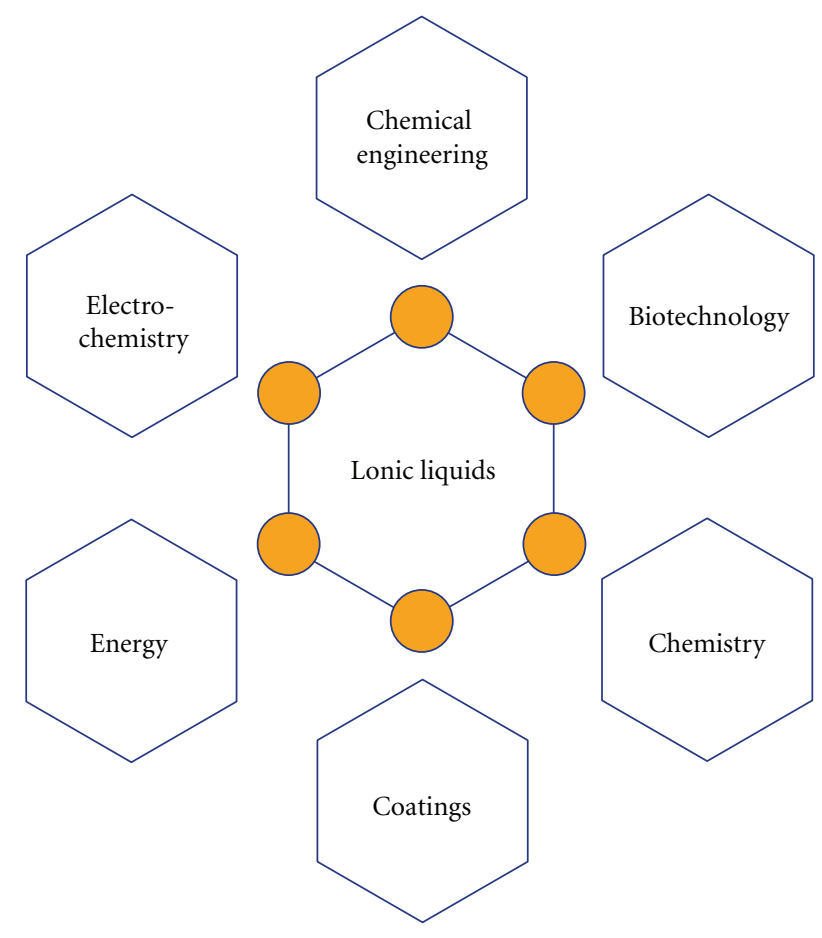

FIgure 1: Applications of ILs.

system [10]. The presence of an abundance of charge carriers means that when ILs are used as solvents, no supporting electrolyte is required for electrochemical experiments and this minimizes waste towards greener site [9].

\section{History of ILs}

The field of ILs has been reviewed by several authors, including Welton [8], Holbrey and Seddon [9], and Seddon [2]. Moreover, ILs have been known for a long time, but their extensive use as solvents in chemical processes for synthesis and catalysis has recently become significant. The discovery date of the first IL is disputed, along with the identity of its discoverer. Ethanolammonium nitrate (m.p. $52-55^{\circ} \mathrm{C}$ ) was reported in 1888 by Gabriel and Weiner [11]. The first RTIL $\left[\mathrm{EtNH}_{3}\right]\left[\mathrm{NO}_{3}\right]$ (melting point $12^{\circ} \mathrm{C}$ ) was discovered in 1914 [12]. This material is probably the first described in the literature that fulfills the definition of ILs used today. In this context it should be noted that at that time Walden had of course no idea of this definition or the whole concept of ILs. Consequently, it is not surprising that at time no attention was paid to the potential of this class of materials. Moreover, Walden had reported the physical properties of ethylammonium nitrate, $\left[\mathrm{C}_{2} \mathrm{H}_{5} \mathrm{NH}_{3}\right] \mathrm{NO}_{3}$, which has a melting point of $12^{\circ} \mathrm{C}$, formed by the reaction of ethylamine with concentrated nitric acid, but interest did not develop until the discovery of binary ILs made from mixtures of aluminum(III) chloride and N-alkylpyridinium [13] or 1,3-dialkylimidazolium chloride [14].

In 1970s and 1980s, Osteryoung et al. [13, 15] and Hussey et al. $[14,16,17]$ carried out extensive research on organic chloride-aluminium chloride ambient temperature ILs and the first major review of ILs was written by Hussey [18]. The ILs based on $\mathrm{AlCl}_{3}$ can be regarded as the first generation of ILs.

In the late 1990s, ILs became one of the most promising chemicals as solvents. An important property of the imidazolium halogenoaluminate salts is that their physical properties such as viscosity, melting point, and acidity could be adjusted by changing the alkyl substituents and the imidazolium/pyridinium and halide/halogenoaluminate ratios [19]. Two major drawbacks for some applications were moisture sensitivity and acidity/basicity. In 1992, Wilkes and Zaworotko obtained second generation of ILs with "neutral" weakly coordinating anions such as hexafluorophosphate $\left(\mathrm{PF}_{6}{ }^{-}\right)$and tetrafluoroborate $\left(\mathrm{BF}_{4}{ }^{-}\right)$, allowing a much wider range of applications [20]. After the first reports on the synthesis and applications of air stable ILs such as 1-n-butyl3-methlyimidazolium tetrafluoroborate ([BMIm] $\left.\left[\mathrm{BF}_{4}\right]\right)$ and 1-butyl-3-methlyimidazolium hexafluorophosphate ([BMIm] $\left.\left[\mathrm{PF}_{6}\right]\right)$, the number of air and water stable ILs has started to increase rapidly [21]. Unlike the chloroaluminate ILs, these ILs could be prepared and safely stored outside of an inert atmosphere. Generally, these ILs are water insensitive; however, the exposure to moisture for a long time can cause some changes in their physical and chemical properties. Therefore, ILs based on more hydrophobic anions such as tri-fluoromethanesulfonate $\left(\mathrm{CF}_{3} \mathrm{SO}_{3}{ }^{-}\right)$, bis(trifluoromethanesulfonyl)imide $\left[\left(\mathrm{CF}_{3} \mathrm{SO}_{2}\right)_{2} \mathrm{~N}^{-}\right]$, and tris(trifluoromethanesulfonyl)methide $\left[\left(\mathrm{CF}_{3} \mathrm{SO}_{2}\right)_{3} \mathrm{C}^{-}\right]$have been developed [22-24]. These ILs have received extensive attention not only because of their low reactivity with water but also because of their large electrochemical windows. Usually these ILs can be well dried to the water contents of below as $1 \mathrm{ppm}$ under vacuum at temperatures between 100 and $150^{\circ} \mathrm{C}$.

\section{Electrochemical Properties of ILs}

ILs are made of positively and negatively charged ions, whereas water and organic solvents, such as toluene and dichloromethane, are made of molecules. The structure of ILs is similar to the table salt such as sodium chloride which contains crystals made of positive sodium ions and negative chlorine ions, not molecules. While salts do not melt below $800^{\circ} \mathrm{C}$, most of ILs remains liquid at room temperature. Since these conventional molten salts exhibit high melting points, their use as solvents in applications is severely limited. However, ILs are liquid generally up to $200^{\circ} \mathrm{C}$. ILs have a wide liquid ranges.

Researchers explained that ILs remain liquid at room temperature due to the reason that their ions do not pack well [25]. Combination of bulky and asymmetrical cations and evenly shaped anions forms a regular structure, namely, a liquid phase. The physical and chemical properties of ILs can be varied over a wide range by the selection of suitable cations and anions. Some of the properties that depend on the cation and anion selection include melting point, viscosity, and solubility characteristics [26]. Most widely 
TABLE 1: List of some abbreviations.

\begin{tabular}{ll}
\hline Abbreviation & Name \\
\hline$[\mathrm{BEIm}]$ & 1-Butyl-3-ethylimidazolium \\
{$[\mathrm{BMIm}] \mathrm{BF}_{4}$} & 1-Butyl-3-methylimidazolium tetrafluoroborate \\
{$[\mathrm{BMIm}] \mathrm{PF}_{6}$} & 1-Butyl-3-methylimidazolium hexafluorophosphate \\
{$[\mathrm{BMIm}] \mathrm{Tf}_{2} \mathrm{~N}_{\mathrm{NTf}}$} & 1-Butyl-3-methylimidazolium bis(trifluoromethylsulfonyl)imide \\
{$[\mathrm{BMP}] \mathrm{Nf}_{2} \mathrm{~N} / \mathrm{NTf}_{2}$} & 1-Butyl-1-methylpyrrolidinium bis(trifluoromethylsulfonyl)imide \\
{$[\mathrm{BMMIm}] \mathrm{Tf}_{2} \mathrm{~N}_{\mathrm{NTf}}$} & 1-Butyl-2,3-dimethylimidazolium bis(trifluoromethylsulfonyl)imide \\
{$[\mathrm{BMIm}] \mathrm{NfO}$} & 1-Butyl-3-methylimidazolium trifluoromethanesulfonate \\
{$[\mathrm{EMIm}] \mathrm{BF}_{4}$} & 1-Ethyl-3-methylimidazoliumtetrafluoroborate \\
{$[\mathrm{EMIm}] \mathrm{Cl}$} & 1-Ethyl-3-methylimidazolium chloride \\
{$[\mathrm{EMIm}] \mathrm{PF}_{6}$} & 1-Ethyl-3-methylimidazolium hexafluorophosphate \\
{$[\mathrm{OMIm}] \mathrm{Tf}_{2} \mathrm{~N} / \mathrm{NTf}_{2}$} & 1-Octyl-3-methylimidazolium bis(trifluoromethylsulfonyl)imide \\
{$[\mathrm{PMP}]$} & 1-Propyl-1-methylpyrrolidinium \\
$\mathrm{TFA}$ & Trifluoroacetate \\
$\mathrm{Tf}_{2} \mathrm{~N} / \mathrm{NTf}$ & Bis(trifluoromethylsulfonyl)imide \\
$\mathrm{TfO}$ & Trifluoromethanesulfonate \\
$\mathrm{BF}$ & Tetrafluoroborate \\
$\mathrm{PF}_{6}$ & Hexafluorophosphate \\
\hline
\end{tabular}

used ILs and their structures are given in Table 1. As solvents, ILs posses several advantages over conventional organic solvents, which make them environmentally compatible [2734].

(i) A diverse range of organic, inorganic, and organometallic compounds are soluble in ILs. The solubility of gases such as $\mathrm{O}_{2}$, benzene, nitrous oxide, ethylene, ethane, and carbon monooxide is also good, which makes them attractive solvent system for catalytic hydrogenations, carbonylations, hydroformylation, and aerobic oxidations.

(ii) Due to the large electrochemical window, they are especially suitable as reaction media for electrochemical (and also chemically induced) polymerization processes leading to conducting polymers.

(iii) ILs are highly polar.

(iv) ILs consist of loosely coordinating bulky ions.

(v) Most of ILs have a liquid window of up to $200^{\circ} \mathrm{C}$ which enables wide kinetic control.

(vi) ILs have high thermal conductivity.

(vii) ILs are immiscible with many organic solvents.

(viii) ILs are nonaqueous polar alternatives for phase transfer processes.

(ix) The solvent properties of ILs can be tuned for a specific application by varying the anion cation combinations.

(x) ILs tend to have good thermal stability and can be liquid over a range of $300^{\circ} \mathrm{C}$. This wide liquid range is distinct advantages over traditional solvent system that have a much narrower liquid range; for example, water has a liquid range of $100^{\circ} \mathrm{C}$ or toluene $206^{\circ} \mathrm{C}$. (xi) The majority of ILs have low volatility. This property makes them easy to contain, use, and transfer and in addition they can be used under high vacuum conditions. This is an important feature that reduces chronic exposure to solvent vapors.

(xii) ILs can be recycled. Recovery and recycling of the catalyst are also possible with the ILs, thus keeping production of waste and loss of valuable catalysts to a minimum.

Properties such as nonflammability, high ionic conductivity, and electrochemical and thermal stability of ILs make them ideal electrolytes in electrochemical devices like in batteries [35-38], capacitors [39-41], fuel cells [42], photovoltaics [43-48], actuators [49], and electrochemical sensors. Recently, ILs have captured the attention of the analysts to use them in different analytical applications as well. ILs can improve separation of complex mixtures of both polar and nonpolar compounds when used either as stationary phase or as additives in gas-liquid chromatography [50-53], liquid chromatography [52], and capillary electrophoresis [54]. They are also used in optical sensors $[55,56]$ and also to enhance the analytical performance of the matrix-assisted laser desorption ionization mass spectrometry (MALDI-MS) [57]. The use of ILs in different applications is determined by their intrinsic properties.

\subsection{Physical Properties of ILs}

3.1.1. Conductivity. In electrochemical experiments, the conductivity of a solvent is of vital importance. ILs have reasonably good ionic conductivities compared with those of organic solvents/electrolyte systems (up to $10 \mathrm{mS} \mathrm{cm}^{-1}$ ) [58]. At elevated temperatures of, for example, $200^{\circ} \mathrm{C}$ a conductivity of $0.1 \Omega^{-1} \mathrm{~cm}^{-1}$ can be achieved for some systems. ILs have advantages over traditional organic solvents 
as their conductivity is intrinsic and they do not require the addition of supporting electrolyte. However, at room temperature their conductivities are usually lower than those of concentrated aqueous electrolytes. Based on the fact that ILs are composed solely of ions, it would be expected that ILs have high conductivities. This is not the case since the conductivity of any solution not only depends on the number of charge carriers but also on their mobility. The large constituent ions of ILs reduce the ion mobility which, in turn, leads to lower conductivities. Furthermore, ion pair formation and/or ion aggregation lead to reduced conductivity. In fact, the change in conductivity with composition in ILs can be attributed almost directly to changes in the viscosity [59]. Hence, ILs of higher viscosity exhibit lower conductivity. Increasing the temperature results in increase in conductivity and decrease in viscosity.

3.1.2. Viscosity. The viscosity of a solvent is an important electrochemical property since high viscosities limit some applications and slow down the rate of diffusion-controlled chemical reactions [60].

As a result of the strong electrostatic and other interaction forces the viscosity of ILs is typically 10 to 100 times higher than that of water or organic solvents [61-64]. The viscosity of IL is affected by the nature of both the cations and anions. Alkyl chain lengthening in the cation leads to an increase in viscosity. This is due to stronger van der waals forces between cations leading to increase in the energy required for molecular motion. The nature of the anion also affects the viscosity of the IL, particularly through relative basicity and the ability to participate in hydrogen bonding. It is found that $\mathrm{PF}_{6}{ }^{-}$and $\mathrm{BF}_{4}{ }^{-}$anions form much more viscous IL due to strong $\mathrm{H}$....F interactions than those IL formed with the weakly basic $\left[\mathrm{NTf}_{2}\right]^{-}$anion, in which the negative charge is quite delocalized over the two sulfoxide groups [65]. Differences in viscosities may also be caused by the size, shape, and molar mass of anion with smaller, lighter, and more symmetric anions leading to more viscous ILs.

3.1.3. Density. ILs are composed only of ions; almost all ILs are denser than water, from 1.0 to $1.6 \mathrm{~g} \mathrm{~cm}^{-3}$ depending on their ion structure. The density has been found to decrease with increasing alkyl chain length on the imidazolium cation $[66,67]$. Similarly, in the ammonium and sulfonium salts, the density decreases with increasing alkyl chain length. This clearly shows that the charged ion unit is heavier than the hydrocarbon chain. Accordingly, the density of ILs is tunable to some extent. The density of aromatic onium salts is higher than that of aliphatic ammonium salts. Generally, density decreases in the order of pyridinium salts > imidazolium salts > aliphatic ammonium salts and piperidinium salts. The densities of ILs are also affected by the anion species. Similarly to the trends for cations, the density of ILs decreases with increasing alkyl chain length of the anion. The density of ILs is increased on the introduction of a heavy chain such as fluoroalkyl chains. For example, 1-ethyl-3-methylimidazolium (EMIm) salts became heavier with the following anion species: $\mathrm{CH}_{3} \mathrm{SO}_{3}{ }^{-}<\mathrm{BF}_{4}{ }^{-}$and $\mathrm{CF}_{3} \mathrm{COO}^{-}<\mathrm{CF}_{3} \mathrm{SO}_{3}{ }^{-}<\left(\mathrm{CF}_{3} \mathrm{SO}_{2}\right)_{2} \mathrm{~N}^{-}<\left(\mathrm{C}_{2} \mathrm{~F}_{5} \mathrm{SO}_{2}\right)_{2} \mathrm{~N}^{-}$. It is easy to understand this order as an effect of formula weight of the ions. However, these tendencies are still empirical and a perfect correlation between ion structure and density is not available.

\subsubsection{Thermal Stability and Decomposition Temperature.} ILs can be thermally stable up to temperatures of $450^{\circ} \mathrm{C}$ with decomposition temperatures around $300-500^{\circ} \mathrm{C}$. The thermal stability of ILs is limited by the strength of their heteroatom-carbon and their heteroatom-hydrogen bonds, respectively [68]. The thermal decomposition temperature decreases as the anion hydrophobicity increases. Halide anions reduce the thermal stability of ILs, with decomposition occurring at least $373 \mathrm{~K}$ below corresponding ILs with nonhalide anions. Relative anion stabilities have been suggested by Huddleston et al. [69] as $\mathrm{PF}_{6}^{-}$[BMIm] $\mathrm{PF}_{6}>\mathrm{NTf}_{2}{ }^{-} \approx \mathrm{BF}_{4}{ }^{-}>$halides. The ILs [BMIm] $\left[\mathrm{PF}_{6}\right]$, [BMIm] $\left[\mathrm{NTf}_{2}\right]$, and [BMIm] $\left[\mathrm{BF}_{4}\right]$ have decomposition temperature of $373 \mathrm{~K}$ higher than the corresponding halide IL $[\mathrm{BMIm}][\mathrm{I}]$. The trend of thermal stability with respect to cation species appears to go as follows: phosphonium > imidazolium $>$ tetraalkyl ammonium pyrrolidinium [70].

3.1.5. Electrochemical Potential Window. The electrochemical potential window (potential region without significant background current) is a key criterion to be considered when any medium is used in electrochemical measurements. A general common feature of ILs is their inherent redoxrobustness, because of the robustness of cations and anions employed for their preparation. ILs generally exhibit a wide potential window, which is highly desirable property for applying the ILs as electrochemical solvents. Typical windows of $4.5-5 \mathrm{~V}$ have been reported for the ILs [71, 72] and even an enlarged electrochemical window up to $7 \mathrm{~V}$ was found for some IL such as 1-butyl-3-methyl-imidazolium tetrafluoroborate [73]. On the whole, this potential window range is equal to slightly wider than that observed in conventional organic electrolytes but largely exceeds that accessible in aqueous electrolytes.

\section{Applications of ILs in Conducting Polymer and Nanoparticle Syntheses}

The utilization of ILs for the synthesis and use of conducting polymers (CPs) brings together two of the most exciting and promising areas of research from recent years. CPs are organic materials that can display electronic, magnetic, and optical properties similar to metals, but that also have the mechanical properties and low density of a polymer. They have the potential to allow the design and fabrication of a vast number of electrochemical devices including photovoltaics, batteries, chemical sensors, supercapacitors, conducting textiles, electrochromics, and electromechanical actuators [74-77].

Research into CPs has been increasingly intense for the last 3 decades, since MacDiarmid, Heeger, and Shirakawa 
published their seminal work on polyacetylene, which demonstrated that the conductivity of these materials can be increased by several orders of magnitude by doping with anions [78, 79]. The importance of these materials and the progress made in this field is reflected in the award of the Nobel Prize for chemistry in 2000 to these founding researchers in this area.

ILs are new solvents for polymerization reactions. The potential benefits of using ILs as electrolytes in CPs devices have been investigated by a number of authors for applications such as actuators [80-88], supercapacitors [89-91], electrochromic devices [83, 92], and solar cells [93] with significant improvements in lifetimes and device performance reported.

The potential of the ILs as media for electrosynthesis of CPs was first demonstrated in the late 1980s for polyfluorene [94, 95], polythiophene [96], or polyphenylene [97] in chloroaluminate ILs. But the high sensitivity of these ILs towards water produced $\mathrm{HCl}$ that led to rapid decomposition of the polymer. One should remember that electrooxidative polymerization involves the coupling between two radical cations of the monomer or of the produced oligomers [98]. It is likely that stabilizing interactions should play a favorable role in the coupling between two charged species, explaining the good results noticed in ILs.

Electrosynthesis of polypyrrole $(\mathrm{pPy})$ in $[\mathrm{BMIm}]\left[\mathrm{PF}_{6}\right]$ on iron and $\mathrm{Pt}[99,100]$ and in [EMIm][OTf], [EMIm] $\left[\mathrm{BF}_{4}\right]$, and [EMIm] $\left[\mathrm{PF}_{6}\right]$ on Pt $[101]$, poly(3,4-ethylenedioxythiophene) (PEDOT) in [EMIm] [NTf 2$],[\mathrm{BMIm}]$ $\left[\mathrm{PF}_{6}\right]$, and $[\mathrm{BMIm}]\left[\mathrm{BF}_{4}\right]$ on $\mathrm{Pt}[102-104]$, or in [EMIm] $\left[\mathrm{BF}_{4}\right]$ on "K-glass" of poly(3-(4-fluorophenyl) thiophene) in [EMMIm] $\left[\mathrm{NTf}_{2}\right]$ and [EEMIm] $\left[\mathrm{NTf}_{2}\right]$ on $\mathrm{Pt}$ [105], poly(paraphenylene) (PPP) in 1-hexyl-3-methylimidazolium tris(pentafluoroethyl) trifluorophosphate on Pt [106], poly(3-chlorothiophene) in [BMIm] $\left[\mathrm{PF}_{6}\right]$ on $\mathrm{Pt}$ [107], and of polythiophene in [EMIm] $\left[\mathrm{NTf}_{2}\right]$ on Pt [108] has been studied.

$\mathrm{Lu}$ et al. [109] reported significant improvements in device performance when the ILs 1-ethyl-3-methylimidazolium hexafluorophosphate, $\left[\mathrm{C}_{2} \mathrm{mim}\right]\left[\mathrm{PF}_{6}\right]$, and 1-ethyl-3methylimidazolium tetrafluoroborate, $\left[\mathrm{C}_{2} \mathrm{mim}\right]\left[\mathrm{BF}_{4}\right]$, were used as supporting electrolytes for $\mathrm{pPy}$ and poly(aniline) actuators and for PEDOT in electrochromic devices, respectively. For the PEDOT study, the IL was also used as the growth medium for the electropolymerization.

Easier or more efficient preparation of CPs films in neat ILs as compared with conventional media was highlighted in some works $[102,107,110,111]$. The electropolymerization of benzene could be achieved with milder conditions in ILs than in the usually employed concentrated sulfuric acid or liquid $\mathrm{SO}_{2}$ [110]. As mentioned by the authors, the use of ILs would enable further studies on the nanoscale with in situ scanning tunneling microscopy (STM) that would be totally precluded in aggressive media like $18 \mathrm{M}$ sulfuric acid or liquid $\mathrm{SO}_{2}$ [110]. Comparison of electropolymerization of pyrrole in neat [EMIm] [OTf], as well as in [EMIm] [OTf] diluted in $\mathrm{CH}_{3} \mathrm{CN}$ or $\mathrm{H}_{2} \mathrm{O}\left(0.1 \mathrm{~mol} \mathrm{~L}^{-1}\right)$, demonstrated that the electropolymerization is more efficient in the neat IL [110]. This result strengthens the idea that ILs are powerful media for the electrochemical generation of CPs films in a greener way.

The influence of the nature of the ILs towards the preparation, the morphology, and the electrochemical activity of polymers has been investigated [101, 102, 108]. The electropolymerization of pyrrole was found to be more efficient in $[\mathrm{EMIm}][\mathrm{OTf}]$ than in $[\mathrm{EMIm}]\left[\mathrm{BF}_{4}\right]$ and [EMIm] $\left[\mathrm{PF}_{6}\right]$, with a formation of smoother and more highly doped polymer films than those from the latter ILs. This result indicates a significant influence of the anion [103]. Thiophene, bithiophene, and terthiophene have been polymerized in imidazolium- and pyrrolidiniumbased $\left[\mathrm{NTf}_{2}\right]$ ILs. Whatever the monomer, use of the pyrrolidinium salts led to polythiophene films that were smoother and denser and had a lower electroactive surface than those from the imidazolium salts [108]. Very striking differences between films grown in conventional solvents and those grown in ILs have been observed using scanning electron microscopy (SEM) [102, 112-116]. Generally, the films grown from ILs appear to be considerably smoother, which may also result in improved conductivities. SEM analysis of poly(thiophene) grown from $\left[\mathrm{C}_{2} \mathrm{mim}\right]\left[\mathrm{NTf}_{2}\right]$ and $\left[\mathrm{C}_{4}\right.$ mpyr $]\left[\mathrm{NTf}_{2}\right]$ reveals a slightly smoother morphology for the poly(thiophene) films from the pyrrolidinium ionic liquid [105].

Dong et al. [117] have investigated the electrochemical polymerization of 1,2-methylenedioxybenzene (MDOB) in an IL 1-butyl-3-methylimidazolium hexafluorophosphate $[\mathrm{BMIm}]\left[\mathrm{PF}_{6}\right]$. This polymer poly(1,2methylenedioxybenzene) (PMDOB) showed good redox activity and stability even in concentrated sulfuric acid. In contrast to acetonitrile containing $0.1 \mathrm{~mol} / \mathrm{L} \mathrm{Bu} \mathrm{BBF}_{4}$, $\mathrm{BMImPF}_{6}$ serves as both the growth medium and an electrolyte. Hence, enhanced electrochemical stability of PMDOB can be easily obtained on repetitive redox cycling; as formed PMDOB represented good electrochromic properties from green grass to opalescent between doped and dedoped states. SEM results demonstrated that smooth and compact PMDOB films composed of ordered nanostructures were obtained, implying their possible utilizations in ionsieving films, ion-selective, and matrices for catalyst particles.

Sekiguchi et al. [118] reported the electropolymerisation of pyrrole in 1-ethyl-3-methylimidazolium triflate, both neat and as a $0.1 \mathrm{M}$ solution in either acetonitrile, or water and observed an improvement in the morphology and electrochemical capacity of the films. Moreover, Pringle et al. [119] reported the electrochemical synthesis of inherently CPs such as polypyrrole in a molecular solvent/electrolyte system such as acetonitrile/lithium perchlorate and IL as well. We use ILs 1-butyl-3methylimidazolium hexafluorophosphate, 1-ethyl-3-methylimidazolium bis(trifluoromethanesulfonyl)amide, and $\mathrm{N}$, $\mathrm{N}$-butylmethylpyrrolidinium bis(trifluoromethanesulfonyl) amide, both as the growth medium and as an electrolyte for the electrochemical cycling of polypyrrole films. Use of the ionic liquid as the growth medium results in significantly altered film morphologies and improved electrochemical activities over traditional organic solvents. 
Pyrrole was electropolymerized in ILs using a platinum wire that was vertically placed into the cell, completely immersed in the ILs and touching the bottom of the cell. It was observed that if the polymerization started as an initial layer on a section of the working electrode, prolonged electrosynthesis led to a growth of the polymer film along the surface of the ionic liquid. This solution-surface electropolymerization was found to occur with a large range of ILs [120]. Fibrils of polypyrrole, polythiophene, and PEDOT were obtained from closely related interfacial polymerization. Using this time a chemical polymerization route, a biphasic ionic liquid/water system with the oxidant dissolved in the aqueous phase and the monomers dissolved in the ILs, allows the polymerization to occur at this RTIL/water interface. The resulting polymers consisted of fibrils about $50 \mathrm{~nm}$ wide and several hundreds of nanometers long [121].

The introduction of the metal nanoparticles into the sensing interface to facilitate the electron transfer can significantly improve the sensitivity [122]. Nanoparticles of noble metals have attracted special interest because they differ from their bulk metal counterparts. Their size controllability, chemical stability, large surface area, thermal stability, good biocompatibility, high catalysis activity, surface tenability, and suitability for many surface immobilization mechanisms make them very advantageous for application in sensors $[121,123]$. For example, $\mathrm{CaCO}_{3}$ nanoparticles can offer a large surface area for adsorption of substances of interest due to their porous structure.

ILs possess pre-organized structures, mainly through hydrogen bonds [124-126] which induce 3D structure dimensionality in these systems. Conversely, aggregates of classical salts display charge-ordered structures. Since ILs can form extended hydrogen bond networks at the liquid state, therefore they demonstrate this very unique property of high self-organization on the nanomolecular scale and can be classified as supramolecular fluids. This nanoscale structural organization of ILs can be used to drive the spontaneous extended ordering of nanomaterials [127, 128]. Some of the classical examples that ILs as designer solvents for the synthesis of metal nanoparticles have illustrated this concept include IL-mediated synthesis of ordered mesoporous materials and microporous aluminophosphates, wherein ILs served as both the solvent and structuredirecting agents $[129,130]$. One another example in this category includes synthesis of protein and silica nanocapsules in $[\mathrm{BMIm}]\left[\mathrm{BF}_{4}\right]$ IL via self-organization process, as was demonstrated recently by Suarez et al. [131]. It has also been established that the properties of imidazolium-based ILs are dependent on their organized nanoaggregates, rather than merely on their isolated cations and anions $[132,133]$. The 3D arrangement of the imidazolium-based ILs is generally formed through chains of the cationic imidazolium rings, which generates supramolecular channels in which anions are typically accommodated as chains [126]. The formation of this 3-D ionic network entails high directional polarizability, which provides an opportunity to adopt a range of external species in either hydrophilic or hydrophobic regions of ILs [134]. Therefore, size and shape of the metal nanoparticles synthesized in ILs are typically modulated by the volume of these 3-dimensionally arranged regions within IL environment. It would probably not be an overstatement to classify ILs as nanostructured solvents, with a potential to direct the tailored synthesis of nanoscale materials.

A series of studies in the literature suggests that ILs interact relatively strongly with the surface of metal nanoparticles, which have been summarized in a recent report [135]. In fact, transition metal nanoclusters and nanoparticles stabilization by imidazolium-based ILs are now considered as a classical stabilization method [135]. Therefore, in account of the previous points, unambiguously ILs are an appealing medium for the formation and stabilization of catalytically active transition metal nanoparticles.

\section{Applications of IL in Gas Sensor}

Extensive efforts have been made to develop new materials and transducers for gas sensing both at room and at high temperatures with particular emphasis on optimizing interface properties among the gas phase, the sensitive materials, and the transducer. IL thin films perform well as sensor interfaces and provide additional control over selectivity and sensitivity when interacting with analytes in the gas phase.

Due to the entire ionic composition, which eliminates the need to add supporting electrolyte, the intrinsic conductivity and negligible vapor pressure ILs are unique compounds to be used in the development of stable electrochemical sensors for gaseous analytes such as $\mathrm{O}_{2}, \mathrm{CO}_{2}$, and $\mathrm{NH}_{3}$ [136-142]. The superoxide radical $\left(\mathrm{O}_{2}{ }^{--}\right)$which is generated in situ by the reduction of $\mathrm{O}_{2}$ was found to be stable in ILs at glassy carbon, gold $(\mathrm{Au})$, or platinum $(\mathrm{Pt})$ electrodes [136-138]. This makes the amperometric detection of $\mathrm{O}_{2}$ possible and the reported solid-state $\mathrm{O}_{2}$ gas sensor based on porous polyethylene supported $[\mathrm{EMIm}]\left[\mathrm{BF}_{4}\right]$ membrane has a wide detection range, high sensitivity, and excellent reproducibility [136]. With increasing levels of $\mathrm{CO}_{2}$ in the sample, cyclic voltammetry shows an increased cathodic peak current from the production of $\mathrm{O}_{2}{ }^{\bullet-}$ radicals together with the decreased peak current from the reverse scan of oxidation. This indicates that the generated $\mathrm{O}_{2}{ }^{--}$radical reacts irreversibly with $\mathrm{CO}_{2}$ to form peroxydicarbonate ion, $\mathrm{C}_{2} \mathrm{O}_{6}{ }^{2-}$ [138].

Cai et al. [143] have developed an $\mathrm{SO}_{2}$ gas sensor resembling the Clark model that employs an IL as the electrolyte, while Wang and coworkers [136, 144] have reported a supported IL membrane-coated oxygen sensor, incorporating 1-ethyl-3-methylimidazolium tetrafluoroborate $\left(\left[\mathrm{C}_{2} \mathrm{MIm}\right]\left[\mathrm{BF}_{4}\right]\right)$ into a polyethylene membrane.

The oxidations of halides, $\mathrm{Cl}^{-}$and $\mathrm{Br}^{-}$, display some different behaviors in ILs than those observed in organic media. Oxidation of $\mathrm{Cl}^{-}$in $[\mathrm{BMIm}]\left[\mathrm{PF}_{6}\right]$, with large concentrations of $[\mathrm{BMIm}][\mathrm{Cl}]$, displays an irreversible process on both platinum and graphite electrode. The main feature was that this oxidation does not lead to chlorine gas evolution but to the formation of oxidation products that stay in the ILs in the form of complexes between $\mathrm{Cl}_{2}$ molecule and chloride ion where the $\mathrm{Cl}_{3}^{-}$is the major product [145-147]. Moreover, 
the electrochemical oxidation of the nitrite ion $\left(\mathrm{NO}_{2}{ }^{-}\right)$ and nitrogen dioxide gas $\left(\mathrm{NO}_{2}\right)$ in $[\mathrm{EMIm}]\left[\mathrm{Tf}_{2} \mathrm{~N}\right]$ has been studied by cyclic voltammetry on Pt electrodes of various sizes [148]. From chronoamperometric measurements, the following solubility values were calculated: $7.5 \mathrm{mM}$ for $\mathrm{NO}_{2}{ }^{-}$ and $51 \mathrm{mM}$ for $\mathrm{NO}_{2}$, indicating that this IL is a potential media for sensing $\mathrm{NO}_{2}$ gas.

Determination of ammonia based on the electrooxidation of hydroquinone in dimethylformamide (DMF) and $[\mathrm{EMIm}]\left[\mathrm{Tf}_{2} \mathrm{~N}\right]$ has also been reported [141]. Ammonia can remove protons from the hydroquinone molecules reversibly and thus facilitate the oxidation process giving a new wave at less positive potentials in the cyclic voltammogram $(\mathrm{CV})$. Similar responses were found in both dimethylformamide and $[\mathrm{EMIm}]\left[\mathrm{Tf}_{2} \mathrm{~N}\right]$. The detection limit of ammonia based on this method is $4.2 \mathrm{ppm}$ in DMF. Solubility and thermodynamic properties of different gases such as $\mathrm{CO}_{2}, \mathrm{H}_{2}$, and $\mathrm{O}_{2}$ in $[\mathrm{BMIm}]\left[\mathrm{PF}_{6}\right]$ have been thoroughly studied [149]. ILs are also utilized as sensing materials for detection of organic vapors by using the quartz crystal microbalance (QCM) technique [150-152].

Yu et al. [153] have developed an integrated sensor that combines electrochemical and piezoelectric transduction mechanisms into a single miniaturized platform for explosives. The IL $[\mathrm{BMIm}]\left[\mathrm{BF}_{4}\right]$ was used as both the electrolyte and the sorption solvent for the two-dimensional electrochemical and piezoelectric gas sensors. Jin and coworkers developed a high-temperature sensor array using a QCMbased sensor [151]. Thin films of seven ILs were employed to provide sensitivity to concentrations of various flammable organic vapors (i.e., ethanol, dichloromethane, benzene, heptane).

Schäfer and coworkers [154] developed a QCM-IL sensor for use as an artificial nose using the ubiquitous $\left[\mathrm{C}_{4} \mathrm{C}_{1} \mathrm{Im}\right]\left[\mathrm{PF}_{6}\right]$. The IL was spin coated onto the surface of a $10 \mathrm{MHz}$ AT-cut quartz crystal with gold electrode. The work specifically studied the response of the sensor to ethyl acetate. The deposition of the IL on the surface of the electrode decreased the resonance frequency of the QCM by $2017 \mathrm{~Hz}$, demonstrating the popularity of QCMs for sensor applications. Goubaidoulline and coworkers opted to entrap IL within nanoporous alumina deposited on the surface of the QCM to eliminate dewetting of the QCM and solving the problem of the soft IL surface [152]. The detection limits for the organic vapors ranged from 321 to $7634 \mathrm{mg} / \mathrm{m}^{3}$. Sensor response times were on the order of minutes.

\section{Application of IL in Electrochemical Sensors}

By far the most highly investigated aspect of IL-based electrochemical sensors is in the realm of electrochemistry, with most of them being based on IL modified electrodes [155-158] wherein the IL typically serves as both binder and conductor. Common attributes observed when incorporating ILs into electrodes include higher conductivity, good catalytic ability, long-term stability (including stability at elevated temperature), superior sensitivity, improved linearity, and better selectivity. Different electrochemical sensors have been developed by using ILs. Several groups had used different kinds of ILs in electrode modification for the design of new electrochemical sensors or as novel electrocatalytic materials [159-164]. Lu et al. [165] used a novel chitosan/1-butyl-3-methylimidazolium hexafluorophosphate $\left(\mathrm{BMIMPF}_{6}\right)$ composite material as a new immobilization matrix to entrap the proteins and studied the electrochemistry behaviors of hemoglobin $(\mathrm{Hb})$ on the glassy carbon electrode. Maleki et al. developed an IL-modified carbon paste electrode (CPE) with 1-octylpyrridinium hexafluorophosphate (OPFP) as binder and further used it for the detection of some electroactive molecules [166-168]. Sun et al. also applied the IL-modified CPE for the investigation of the direct electrochemistry of hemoglobin [169-171].

Sun et al. [172] have used hydrophilic IL 1-ethyl3-methylimidazolium tetrafluoroborate $[\mathrm{EMIm}]\left[\mathrm{BF}_{4}\right]$ as a modifier in the CPE to make a new kind of IL-modified carbon paste electrode (IL-CPE). The fabricated IL-CPE showed good electrocatalytic behaviors towards the oxidation of metol with the enhancement of the redox peak current and the decrease of the peak-to-peak separation with a detection limit of $2.0 \times 10^{-6} \mathrm{~mol} \mathrm{~L}^{-1}(3 \sigma)$. The established method was successfully applied to the synthetic samples and photographic solutions detection with good recovery.

Xiao et al. [173] described the carbon nanotube (CNT)/Ruthenium (Ru), Pd, and Au/IL composite electrode for the fabrication of a nonenzymatic glucose sensor. Electrochemical experiments show that the PtRu- $(1: 1$, i.e., ratio of $\left.\left(\mathrm{H}_{2} \mathrm{PtCl}_{6}\right) /\left(\mathrm{RuCl}_{3}\right)\right)$ multiwalled carbon nanotube- (MWNT-) IL nanocomposite-modified glassy carbon electrode (PtRu(1:1)-MWNT-IL/GCE) has smaller electron transfer resistance and larger active surface area than $\operatorname{PtRu}(1: 1) / G C E, \quad \operatorname{PtRu}(1: 1)$-MWNT/GCE, $\operatorname{PtPd}(1: 1)$-MWNT-IL/GCE, and PtAu(1:1)-MWNTIL/GCE. The PtRu(1:1)-MWNT-IL/GCE also presents stronger electrocatalytic activity towards the glucose oxidation than other electrodes. At $-0.1 \mathrm{~V}$, the electrode responds linearly to glucose up to $15 \mathrm{mM}$ in neutral media, with a detection limit of $0.05 \mathrm{mM}(\mathrm{S} / \mathrm{N}=3)$ and detection sensitivity of $10.7 \mu \mathrm{Acm}^{-2} \mathrm{mM}^{-1}$. Meanwhile, the interference of ascorbic acid, uric acid, acetamidophenol, and fructose is effectively avoided. The as-made sensor was applied to the determination of glucose in serum and urine samples. The results agreed closely with the results obtained by a hospital. This novel nonenzyme sensor thus has potential application in glucose detection.

Jabbar et al. [174] have found the excellent electrocatalytic reductive dechlorination of 1,1 bis $(p$ chlorophenyl) 2,2,2-trichloroethane (DDT) in the IL 1butyl-3-ethylimidazolium tetrafluoroborate $\left([\mathrm{BMIm}]\left[_{\left.\left[\mathrm{BF}_{4}\right]\right)}\right.\right.$ in the presence of a cobalamin derivative afforded 1,19(ethylidene) bis(4-chlorobenzene) (DDO) and 1,19(ethenylidene) bis(4-chlorobenzene) (DDNU) with 1,19(2-chloroethylidene) bis(4-chlorobenzene) (DDMS); the enhanced reactivity, as well as the recyclability of the cobalamin derivative catalyst in IL, makes the present system more efficient for the development of green technologies.

Safavi et al. [168] have constructed a a nonenzymatic composite electrode by mixing the nanoscale $\mathrm{Ni}(\mathrm{OH})_{2}$ with 
graphite powder and $[\mathrm{Opyr}]\left[\mathrm{PF}_{6}\right]$, which showed excellent electocatalytic activity towards oxidation of glucose in an alkaline solution.

The mechanism of this catalytic detection is as follows:

$$
\mathrm{Ni}(\mathrm{OH})_{2}+\mathrm{OH}^{-} \longrightarrow \mathrm{NiO}(\mathrm{OH})+\mathrm{H}_{2} \mathrm{O}+\mathrm{e}^{-}
$$

$\mathrm{NiO}(\mathrm{OH})+$ glucose $\longrightarrow \mathrm{Ni}(\mathrm{OH})_{2}+$ glucono- $\delta$-lactone

Ding et al. [175] have used IL, 1-(2-hydroxyethyl)-3methyl imidazolium tetrafluoroborate ([HEMIm] $\left.\left[\mathrm{BF}_{4}\right]\right)$, as the supporting electrolyte for direct electrochemical response of Myoglobin (Myb) at the basal plane graphite (BPG) electrode. Both anodic and cathodic peak currents increased linearly with the potential scan rate. Compared with the supporting electrolyte of phosphate buffer, [HEMIm] $\left[\mathrm{BF}_{4}\right]$ played an obvious promotion for the direct electron transfer between Myb and the BPG electrode. Further investigation suggested that Myb was adsorbed tightly on the surface of the BPG electrode in the presence of [HEMIm] $\left[\mathrm{BF}_{4}\right]$ to form a stable, approximate monolayer Myb film. Myb adsorbed on the BPG electrode surface showed a remarkable electrocatalytic activity for the reduction of oxygen in a $[\mathrm{HEMIm}]\left[\mathrm{BF}_{4}\right]$ aqueous solution. Based on these, a thirdgeneration sensor could be constructed to directly detect the concentration of oxygen in aqueous solution with a limit of detection of $2.3 \times 10^{-8} \mathrm{M}$.

$\mathrm{Tu}$ and coworkers [176] developed a composite material based on single-walled carbon nanotube (SWCNT), a water-insoluble porphyrin (hydroxyferriprotoporphyrin, hematin), and $[\mathrm{BMIm}]\left[\mathrm{PF}_{6}\right]$. This composite material was used to modify a GC electrode in order to study the direct electrochemistry and electrochemical property of porphyrin. The porphyrin dissolved in $[\mathrm{BMIm}]\left[\mathrm{PF}_{6}\right]$ can be self-assembled on SWCNT by $\pi-\pi$ noncovalent interaction, which leads to good dispersion of the SWC$\mathrm{NTs}$ in the $[\mathrm{BMIm}]\left[\mathrm{PF}_{6}\right]$ and a direct electrochemical response corresponding to the $\mathrm{Fe}^{3+} / 2+$ redox couple. The presence of SWCNT and $[\mathrm{BMIm}]\left[\mathrm{PF}_{6}\right]$ produces a synergic effect that accelerates the electron-transfer between porphyrin and the electrode. As a consequence, the porphyrin/SWCNT/[BMIm] $\left[\mathrm{PF}_{6}\right]$-modified GC showed excellent electrocatalytic activity towards the reduction of trichloroacetic acid (TCA). This study provides a facile way for preparing biofunctional materials, accelerating electrontransfer, and extending the application of porphyrins/ILbased composite materials in sensor applications.

Singh et al. [177] developed a greener electrochemical method for a chemical warfare agent (CWA) using triethyl sulfonium bis(trifluoromethylsulfonyl)imide (TSBTSI). Addition of CWA nitrogen mustard-2 (NM-2) to TSBTSI showed a new peak in addition to an enhancement in peak current than observed for blank TSBTSI. The calculated diffusion coefficient for NM-2 in TSBTSI and Acetonitrile-TBAP was found to be $2.14 \times 10^{-7} \mathrm{~cm}^{2} \mathrm{~s}^{-1}$ and $1.57 \times 10^{-4} \mathrm{~cm}^{2} \mathrm{~s}^{-1}$, respectively. The linear response was obtained in the range of $2.94 \times 10^{-5}$ to $1.17 \times 10^{-3} \mathrm{M}$ with the correlation coefficient 0.9977 and the detection limit of $1.47 \times 10^{-5} \mathrm{M}(\mathrm{s} / \mathrm{n}=3)$ with chronoamperometric method. Electrochemical impedance spectroscopy results revealed an enhancement of solution conductivity after the addition of NM-2 to TSBTSI. The large number of available IL based on the combination of anion and cation and their unique properties allows scope for the possible electrochemical detection of toxic CWAs in a greener way.

\section{Application of IL in Electrochemical Biosensors}

Biosensors are small devices employing biochemical molecular recognition properties as the basis for a selective analysis. The major processes involved in any biosensor system are (i) analyte recognition, (ii) signal transduction, and (iii) readout. In an electrochemical biosensor, a molecular sensing device couples a biological recognition element to an electrode transducer, which converts the biological recognition event into an electrical signal.

ILs have shown good compatibility with biomolecules and enzymes and even whole cells are active in various ILs. [BMIm] $[\mathrm{Cl}]$ was found miscible with silk, which is an attractive biomaterial with excellent mechanical properties and biocompatibility. The patterned films cast from this silk-IL solution supported normal cell proliferation and differentiation [178]. Recently, some authors have reported increased stability of enzymes in ILs compared with stability in some organic solvents [179-181]. ILs were also found to act as agents to stabilize proteins effectively at elevated temperatures [182]. Laszlo and Compton have also reported the catalysis of hemin activated by an electron acceptor in IL solutions and it was found that the activity of hemin increased with the enhanced amount of IL in the methanolIL system [179].

Dramatically enhanced activity and thermal stability of horseradish peroxide (HRP) were obtained when it was immobilized in the $[\mathrm{BMIm}]\left[\mathrm{BF}_{4}\right]$-based sol-gel matrix [183]. The IL was used as a template solvent for the silica gel matrix via a simple sol-gel method via hydrolysis of tetraethyl orthosilicate in $[\mathrm{BMIm}]\left[\mathrm{BF}_{4}\right]$. This particular HRP-immobilized sol-gel matrix was further used in amperometric biosensors [184]. The novel amperometric hydrogen peroxide biosensor based on this ionogel exhibited excellent stability and sensitivity. The detection limit for hydrogen peroxide is reported to be $1.1 \mu \mathrm{M}$.

Direct electrochemical reduction of hemin has been studied by cyclic voltammetry and chronocoulometry in the ILs, $[\mathrm{BMIm}]\left[\mathrm{PF}_{6}\right]$ and $[\mathrm{OMIm}]\left[\mathrm{PF}_{6}\right]$ [185]. NMethylimidazole- (NMI-) ligated hemin had a lower $E_{1 / 2}$ than pyridine-ligated hemin in both ILs, which is consistent with the stronger electron donor characteristic of NMI. It was further discovered that while hemin is electrochemically active in IL, its behavior is modified by the ligand field strength and surface adsorption phenomena at the working electrode. Electrochemistry and electrocatalysis of a number of heme proteins entrapped in agarose hydrogel films in $[\mathrm{BMIm}]\left[\mathrm{PF}_{6}\right]$ have also been investigated [186]. UV-Vis and FTIR spectroscopy show that the heme proteins retain their native structure in agarose film. CV shows that the direct electron transfer between the heme proteins and glassy 
carbon electrode (GCE) is quasireversible in [BMIm] $\left[\mathrm{PF}_{6}\right]$. The redox potentials for hemoglobin $(\mathrm{Hb})$, myoglobin, HRP, cytochrome $\mathrm{c}$, and catalase were found to be lower than those in aqueous solution, indicating the catalytic effect in the IL matrix. The heme proteins can catalyze electroreduction of trichloroacetic acid and tert-butyl hydroperoxide in [BMIm] [PF 6 [186]. Direct electrochemical response of HRP [187], myoglobin [188], and Hb [169] has been observed on IL-modified electrodes.

Zhao et al. [155] mixed MWCNTs with the 1-octyl 3methylimidazolium hexafluoro phosphate, by grinding them together in a mortar to create a gel-like paste which was then applied to the surface of a cleaned GC electrode. Using a platinum wire and a saturated calomel electrode as auxiliary and reference electrodes, respectively, CVs were measured for dopamine in phosphate buffer (PB) for both the MWCNTIL-modified GC electrode and a bare GC electrode. In both cases, two pairs of redox peaks characteristic to dopamine were observed. An immediate advantage of the MWCNTIL-modified electrode (ME) was a larger peak current with smaller peak separations, an indication of faster electron transport to the electrode surface. Similar measurements for ascorbic acid and uric acid revealed that the anodic peak potentials were, respectively, shifted more negative (by $\sim 0.31 \mathrm{~V})$ and more positive $(\sim 0.02 \mathrm{~V})$, when employing the MWCNT-IL-modified electrode compared with GC. This feature helps to eliminate overlap between dopamine's anodic peak and the anodic peaks of ascorbic acid and uric acid as occured at a GC electrode. Further resolution was achieved by using differential pulse voltammetry. At pH 7.08, the ascorbic acid and uric acid peaks are separated from dopamine by 0.20 and $0.15 \mathrm{~V}$, respectively. Hence, dopamine could be determined in the presence of uric acid and ascorbic acid in 100-fold excess. The detection limit of dopamine was determined to be $1.0 \times 10^{-7} \mathrm{M}$ with a linear dynamic range up to $1.0 \times 10^{-4} \mathrm{M}$.

In fabricating electrochemical biosensing layers, the CNT/IL-based composite materials are advantageous due to the following reasons: (i) retain inherent mechanical, electrical, and thermal properties of CNT (e.g., large surface area, good electroconductive nanowires, etc.), (ii) better solvent and conductivity property of ILs (e.g., large potential window, ion conductor, etc.), and (iii) proper interaction between CNT and ILs. Direct physical adsorption is one of the most widely used approaches to immobilize biomolecules on CNT/IL-modified sensing layers. However, the preparation of CNT/IL pastes and composites by direct mixing of the CNT with a suitable IL has been limited by the very high background currents which would limit monitoring the faradaic current, and hence, limit the use of such a combination. This increased capacitive charging current can be reduced using steady-state linear sweep voltammetry at rotating disk electrodes, as suggested by Compton group [189].

Most of carbon paste electrodes (CPEs) reported for electroanalysis are based on incorporation of a sensing material into the carbon paste. The carbon paste usually consists of graphite powder dispersed in a nonconductive mineral oil such as paraffin. Incorporation of mineral oil gives some disadvantages. Mineral oil is not component fixed since it is derived from refining of petroleum and processing of crude oil. As a result, contaminants or matrix components may unpredictably effect on detection and analysis. In addition, the mechanical stability of CPEs rests somewhere between that of liquid membrane electrodes and solid state electrodes. CPEs have attracted attention as ion selective electrodes mainly due to their improved renewability, stable response, and low ohmic resistance when compared to membrane electrodes [190-193].

Musameh and Wang [194] have prepared IL-carbon composite glucose biosensor with the help of n-octylpyridinium hexafluorophosphate $\left(\mathrm{nOPPF}_{6}\right)$ and graphite powder and they found that the electrocatalytic properties of the ILs are not impaired by their association with the graphite powder. The marked electrocatalytic activity towards hydrogen peroxide permits effective amperometric biosensing of glucose in connection with the incorporation of glucose oxidase within the three-dimensional IL/graphite matrix. The prepared composite film shows accelerated electron transfer with low background current and improved linearity. A comparison was made between IL-based biocomposite devices and conventional mineral oil/graphite biocomposite and it is found that IL-based biocomposite devices performed well with good linearity. In this work the influence of the IL and glucose oxidase (GOx) loading was also studied towards the amperometric and voltammetric responses.

Kachoosangi et al. [195] developed a new composite material based on MWCNT and $[\mathrm{Opyr}]\left[\mathrm{PF}_{6}\right]$, which showed an extremely low capacitive and background current compared to graphite and mineral oil-based CPEs. The new composite material combines the unique and attractive electrocatalytic behaviour of CNTs and $[\mathrm{Opyr}]\left[\mathrm{PF}_{6}\right]$, with very low background current and mechanically robust structure compared to many other forms of composite and paste electrodes made from CNTs and other ILs. Wang et al. [196] prepared a composite material based on [BNIm] $\left[\mathrm{BF}_{4}\right]$, MWCNT, and chitosan successfully used for the electrochemical oxidation of NADH.

CNT and carbon microbeads were incorporated into the water-immiscible [BMIm] $\left[\mathrm{PF}_{6}\right]$ [197]. In particular, CNT has been demonstrated to be physically cross-linked in the viscous ILs, forming gels [198]. These carbon-composite materials mixed with $\mathrm{HRP}, \mathrm{Hb}$, or glucose oxidase were dropped onto gold or GCEs. The direct electrochemistry of heme proteins or glucose oxidase immobilized at these carbon materials has been investigated and this promising biointerface promoted direct electron transfer and biocatalytic performance [198-200].

CNT-modified GCEs showed enhanced sensitivity and stability in the oxidation of phenolic compounds [199]. The CNT-modified electrodes were also found to show good electrocatalytic ability to biomolecules such as dopamine (DA), ascorbic acid (AA), and dihydronicotinamide adenine dinucleotide (NADH) [199-203]. CNTs usually exist as tangled bundles that are difficult to dissolve in both aqueous and organic media. However, they can be well individualized in ILs due to "cation- $\pi$ " interactions and a 
CNTs-IL gel can easily be prepared using IL as the binder [204], where the CNTs greatly enhance the conductivity of the system. Electrochemical functionalization of single wall carbon nanotubes in $[\mathrm{BMIm}]\left[\mathrm{PF}_{6}\right]$ was used to make a glucose sensor by covalently binding glucose oxidase (GOD) to the modified nanotube [205].

Zhang et al. [206] have prepared a novel polyanilineIL-carbon nanofiber (PANI-IL-CNF) composite by in situ one-step electropolymerization of aniline in the presence of IL and CNF for fabrication of amperometric biosensors for phenol. This biosensor exhibited a wide linear response to catechol ranging from $4.0 \times 10^{-10}$ to $2.1 \times 10^{-6} \mathrm{M}$ with a high sensitivity of $296 \pm 4 \mathrm{AM}^{-1} \mathrm{~cm}^{-2}$, a limit of detection down to $0.1 \mathrm{nM}$ at the signal-to-noise ratio of 3 , and applied potential of $-0.05 \mathrm{~V}$. According to the Arrhenius equation, the activation energy for enzymatic reaction was calculated to be $38.8 \mathrm{~kJ} \mathrm{~mol}^{-1}$ using catechol as the substrate. The apparent Michaelis-Menten constants of the enzyme electrode were estimated to be $1.44,1.33,1.16$, and $0.65 \mu \mathrm{M}$ for catechol, p-cresol, phenol, and m-cresol, respectively. The functionalization of CNF with PANI in IL provided good biocompatible platform for biosensing and biocatalysis.

Tao et al. [156] compared the interaction of $[\mathrm{BMIm}]\left[\mathrm{BF}_{4}\right]$ with three different types of carbonaceous material for use in MEs: acid-treated MWCNTs (AMWCNTs), pristine MWCNTs (PMWCNTs), and pyrolytic graphite powder (PGP). To prepare the MEs, each carbon material was ground with the water-miscible IL $[\mathrm{BMIm}]\left[\mathrm{BF}_{4}\right]$, resulting in AMWCNT-[BMIm] $\left[\mathrm{BF}_{4}\right]$, PMWCNT-[BMIm] $\left[\mathrm{BF}_{4}\right]$, and PGP-[BMIm] $\left[\mathrm{BF}_{4}\right]$ composites which were then applied on to a polished GC electrode surface. The composite films were presumably attached through electrostatic adsorption between the negatively charged surface and the positive component of the IL. The conductivities and optical properties of each composite were compared using ac impedance and Raman spectroscopy. $[\mathrm{BMIm}]\left[\mathrm{BF}_{4}\right]$ formed a gel when ground with MWCNTs, whereas a viscous liquid resulted from the admixture of [BMIm] $\left[\mathrm{BF}_{4}\right]$ with PGP. Raman spectroscopy demonstrated that both AMWCNs and PMWCNs electrostatically interact with $[\mathrm{BMIm}]\left[\mathrm{BF}_{4}\right]$ while no such interaction occurs between PGP and $[\mathrm{BMIm}]\left[\mathrm{BF}_{4}\right]$, accounting for the fact that PGP-[BMIm] $\left[\mathrm{BF}_{4}\right]$ blend fails to form gel. Data from ac impedance and $\mathrm{CV}$ measurements (using potassium ferricyanide, $\mathrm{K}_{3}\left[\mathrm{Fe}(\mathrm{CN})_{6}\right]$ ) demonstrated that the ME conductivity increases in the following order: PGP$[\mathrm{BMIm}]\left[\mathrm{BF}_{4}\right]<$ PMWCNT-[BMIm] $\left[\mathrm{BF}_{4}\right]<$ AMWCNT$[\mathrm{BMIm}]\left[\mathrm{BF}_{4}\right]$. Thus, the AMWCNT-[BMIm] $\left[\mathrm{BF}_{4}\right] \mathrm{ME}$ system was selected for additional bioelectrochemical studies. For these experiments, the redox biocatalyst (i.e., hemin, hemoglobin ( $\mathrm{Hb})$, or HRP) was initially mixed with the IL prior to grinding with AMWCNTs and the ensuing gel fixed to the GC electrode by rubbing. CV measurements showed a pair of reversible peaks attributed to the heme $\mathrm{Fe}^{3+} / \mathrm{Fe}^{2+}$ redox couple for all three MEs. The hemin, $\mathrm{Hb}$, and HRP-AMWCNT-[BMIm] $\left[\mathrm{BF}_{4}\right]$ MEs all demonstrated electrocatalytic behavior towards $\mathrm{H}_{2} \mathrm{O}_{2}$, with the fastest electron transfer rate observed for the hemin-based ME. The MEs were reproducibly fabricated and reportedly exhibited good stability, retaining $\geq 60 \%$ of the peak current after 20 cycles.

A novel amperometric biosensor was fabricated based on the immobilization of cholesterol oxidase (ChOx) into a cross-linked matrix of chitosan- (Chi-) IL (1-butyl-3methylimidazolium tetrafluoroborate) by Gopalan et al. [207]. In this study, the surface of bare electrode (indium tin oxide-coated glass) was modified with the electrodeposition of Au particles onto thiol- (SH-) functionalized MWNTs. The presence of Au particles in the matrix of CNTs provides an environment for the enhanced electrocatalytic activities. The MWNT(SH)-Au/Chi-IL/ChOx biosensor exhibited a linear response to cholesterol in the concentration range of $0.5-5 \mathrm{mM}$ with a correlation coefficient of 0.998 , good sensitivity $\left(200 \mu \mathrm{AM}^{-1}\right)$, a low response time (approximately $7 \mathrm{~s}$ ), repeatability (R.S.D value of $1.9 \%$ ), and long-term stability (20 days with a decrease of $5 \%$ response). The synergistic influence of MWNT(SH), Au particles, Chi, and IL contributes to the excellent performance for the biosensor.

Kachoosangi et al. [195] prepared a new composite electrode using MWCNT and the IL n-octylpyridinum hexafluorophosphate (OPFP). One major advantage of this electrode compared to other electrodes using carbon nanotubes and other ILs is its extremely low capacitance and background currents. A 10\% (w/w) loading of MWCNT was selected as the optimal composition based on voltammetric results, as well as the stability of the background response in solution. The new composite electrode showed good activity towards hydrogen peroxide and $\mathrm{NADH}$, with the possibility of fabricating a sensitive biosensor for glucose and alcohol using glucose oxidase and alcohol dehydrogenase, respectively, by simply incorporating the specific enzyme within the composite matrix. The marked electrode stability and antifouling features towards NADH oxidation was much higher for this composite compared to a bare glassy carbon electrode. While a loading of $2 \%$ MWCNT showed very poor electrochemical behavior, a large enhancement was observed upon gentle heating to $70^{\circ} \mathrm{C}$, which gave a response similar to the optimum composition of $10 \%$. The ease of preparation, low background current, high sensitivity, stability, and small loading of nanotubes using this composite can create new novel avenues and applications for fabricating robust sensors and biosensors for many important species.

The composite film based on Nafion and hydrophobic IL 1-butyl-3-methyl-imidazolium hexafluorophosphate [BMIm] $\left[\mathrm{PF}_{6}\right]$ was explored by Chen et al. [208]. In this work, nafion was used as a binder to form nafion-ILs composite film and help [BMIm] $\left[\mathrm{PF}_{6}\right]$ effectively adhered on GCE. X-ray photoelectron spectroscopy (XPS), CV, and electrochemical impedance spectroscopy (EIS) were used to characterize this composite film, showing that the composite film can effectively adhere on the GC electrode surface through Nafion interacting with $[\mathrm{BMIm}]\left[\mathrm{PF}_{6}\right]$ and $\mathrm{GC}$ electrode. Meanwhile, doping $[\mathrm{BMIm}]\left[\mathrm{PF}_{6}\right]$ in Nafion can also effectively reduce the electron transfer resistance of nafion. The composite film can be readily used as an immobilization matrix to entrap horseradish peroxidase (HRP). A pair of well-defined redox peaks of HRP was obtained at the HRP/Nafion-[BMIm] $\left[\mathrm{PF}_{6}\right]$ composite film-modified 
GC electrode through direct electron transfer between the protein and the underlying electrode. HRP can still retain its biological activity and enhance electrochemical reduction towards $\mathrm{O}_{2}$ and $\mathrm{H}_{2} \mathrm{O}_{2}$. It is expected that this composite film may find more potential applications in biosensors and biocatalysis.

An organophosphorus hydrolase $(\mathrm{OPH})$ immobilized on MWCNT/IL where IL $=[\mathrm{BMIm}]\left[\mathrm{BF}_{4}\right],[\mathrm{BMIm}]\left[\mathrm{PF}_{6}\right]$, or $[\mathrm{BMIm}]\left[\mathrm{NTf}_{2}\right]$-modified composite electrodes showed higher sensitivity and better stability in detecting organophosphate [209]. The modification of MWCNTs with these different ILs allowed high dispersion of CNT bundles and the formation of a 3D-network structure, good compatibility with $\mathrm{OPH}$, and accelerated electron-transfer reaction at the interface. The electron-transfer rate of the three modified electrodes increased after the incorporation of $\mathrm{OPH}$ in the following order: $\mathrm{OPH} /[\mathrm{BMIm}]\left[\mathrm{PF}_{6}\right]<$ $\mathrm{OPH} /[\mathrm{BMIm}]\left[\mathrm{BF}_{4}\right]<\mathrm{OPH} /[\mathrm{BMIm}]\left[\mathrm{NTf}_{2}\right]$. Sun et al. [210] developed two methods, namely, casting and rubbing methods to prepare the Fc-filled SWCNT-modified GC electrode which showed excellent mediation of $\mathrm{H}_{2} \mathrm{O}_{2}$ based on the $\mathrm{Fc} / \mathrm{Fc}^{+}$couple used as electron-transfer mediator for oxidation of $\mathrm{H}_{2} \mathrm{O}_{2}$ to $\mathrm{O}_{2}$ and reduction of $\mathrm{H}_{2} \mathrm{O}_{2}$ to $\mathrm{H}_{2} \mathrm{O}$.

Gels of acid treated multiwall CNTs with water-miscible IL $[\mathrm{BMIm}]\left[\mathrm{BF}_{4}\right]$ were made by grinding them together [156]. GCE modified by this gel was used in direct electrochemical study of heme proteins ( $\mathrm{Hb}$ and HRP). The heme proteins entrapped in CNTs-[BMIm] $\left[\mathrm{BF}_{4}\right]$ gel exhibit good biocatalytic activity towards $\mathrm{H}_{2} \mathrm{O}_{2}$ due to the biocompatibility of $[\mathrm{BMIm}]\left[\mathrm{BF}_{4}\right]$. This composite material has shown to keep the bioactivity and to facilitate direct electron transfer of heme proteins. Carbon fiber microelectrode has also been modified by CNTs-IL gel and used in bioelectrochemical studies [158]. The carbon fiber microelectrode modified by CNTs-IL gel promotes greatly the direct electron transfer of glucose oxidase and exhibits effective catalytic activity to biomolecules, such as DA, AA, and NADH. IL has also been used as binder to modify electrode surface of multiwall carbon nanotubes. This construction has better electrochemical properties than by chitosan or Nafionmodified electrodes. The GOD adsorbed at this modified electrode shows good stability and electrocatalytic activity to glucose with a broad linear concentration range up to $20 \mathrm{mM}$ [155].

Rahimi et al. [211] developed a nanocomposite material consisting of amine functionalized multiwalled carbonnanotubes and an IL, 1-butyl-3-methylimidazolium tetrafluoroborate and further it was used in construction of a novel catalase-based biosensor for the measurement of hydrogen peroxide. The modified electrode exhibited a quasireversible $\mathrm{CV}$ corresponding to the $\mathrm{Fe}^{2+} / \mathrm{Fe}^{3+}$ redox couple in the heme prosthetic group of catalase with a formal potential of $-460 \mathrm{mV}$ in $0.1 \mathrm{M}$ phosphate buffer solution at $\mathrm{pH}=$ 7.0. The nanocomposite film showed an obvious promotion of the direct electron transfer between catalase and the underlying electrode. The apparent charge transfer rate constant and transfer coefficient for electron transfer between the electrode surface and enzyme were reported as $2.23 \mathrm{~s}^{-1}$ and 0.45 , respectively. The immobilized catalase exhibited a relatively high sensitivity $(4.9 \mathrm{nA} / \mathrm{nM})$ towards hydrogen peroxide.

Graphene [212], known as single layer graphite, has attracted intensive scientific interest in recent years due to its two-dimensional and unique physical properties, such as high intrinsic carrier mobility at room temperature $\left(\approx 10^{5} \mathrm{~cm}^{2} / \mathrm{V} \cdot \mathrm{s}\right)$, excellent mechanical strength, and electrical and thermal conductivity comparable to the in-plane value of graphite [213]. Owing to the unique properties [214, 215] graphene/IL-based composite materials have been widely used in fabricating electrochemical biosensors [216].

Shan et al. [217] reported the first graphene-based glucose biosensor with graphene/polyethyleniminefunctionalized IL nanocomposites-modified electrode which exhibits wide linear glucose response (2 to $14 \mathrm{mM}$, $R=0.994$ ), good reproducibility (relative standard deviation of the current response to $6 \mathrm{mM}$ glucose at $-0.5 \mathrm{~V}$ was $3.2 \%$ for 10 successive measurements), and high stability (response current $+4.9 \%$ after 1 week). In this work, direct electrontransfer of $\mathrm{GOx}$ and electrocatalytic activity towards the reduction of $\mathrm{O}_{2}$ and $\mathrm{H}_{2} \mathrm{O}_{2}$ at the polyvinylpyrrolidoneprotected graphene/polyethyleniminefunctionalized IL/GOx-modified electrode has been demonstrated.

IL-graphene-based biosensors have been reported for direct electron transfer and detection of different targets also such as NADH and guanine [218, 219]. These results suggest that IL-graphene hybrid nanosheets due to good dispersibility and long-term stability are expected to be useful materials for enhancing the electrochemical performance for the detection of different target molecules in electroanalytical applications.

\section{Conclusions}

ILs are solvents that can be designed for special applications either by synthesizing new ILs or by paring different cations and anions to fine-tune the properties of a particular IL. In this review article we have tried to give an overview on the importance of ionic liquids for the synthesis of conducting polymers and nanoparticle. Moreover, electrochemical methods such as potentiometry, voltammetry, and QCM have been used in ILs to develop new generation of ion selective sensors, voltammetric devices, gas sensors, and electrochemical biosensors.

The good catalytic ability of IL-based composite materials together with the simple preparation procedure greatly promotes the development of highly sensitive, selective, and reproducible microelectrode to be used in electrochemical biosensors and other bioelectrochemical devices. Taking advantage of the fact that ILs could be used as both immobilizing matrices to entrap heme proteins and enzymes as the electron-transfer promoters to achieve direct electrontransfer between the redox proteins and underlying electrodes hence provided a good electrocatalytic sensing platform for various substrates. The fundamental understanding of the underlying biochemistry, surface chemistry, electrochemistry, material chemistry, and technological advances is needed in order to enhance the capabilities and improve 
the reliability, portability, and functionality of IL-based biosensors to bring the biosensors in real applications. The still rising interest in ILs in various fields of chemistry will surely lead to a rising output of products papers, stimulating further studies. It can be expected that ILs in electrochemical sensing are a promising and exciting area of research and definitely need further exploration. Combination of ILs with electrochemical sensors has the potential to broaden or even revolutionize the range of analytical methods.

\section{References}

[1] J. G. Huddleston, H. D. Willauer, R. P. Swatloski, A. E. Visser, and R. D. Rogers, "Room temperature ionic liquids as novel media for "clean" liquid-liquid extraction," Chemical Communications, no. 16, pp. 1765-1766, 1998.

[2] K. R. Seddon, "Ionic liquids for clean technology," Journal of Chemical Technology and Biotechnology, vol. 68, no. 4, pp. 351-356, 1997.

[3] V. Koch, C. Nanjundiah, and R. Carlin, "Hydrophobic ionic liquids," US Patent 1998, 5827602.

[4] C. Reichardt, "Solvents and solvent effects: An introduction," Organic Process Research and Development, vol. 11, no. 1, pp. 105-113, 2007.

[5] W. Sundermeyer, "Fused salts and their use as reaction media," Angewandte Chemie International Edition, vol. 4, pp. 222-238, 1965.

[6] J. Fuller, R. T. Carlin, and R. A. Osteryoung, "The room temperature ionic liquid 1 -ethyl-3-methylimidazolium tetrafluoroborate: electrochemical couples and physical properties," Journal of the Electrochemical Society, vol. 144, no. 11, pp. 3881-3886, 1997.

[7] B. M. Quinn, Z. Ding, R. Moulton, and A. J. Bard, "Novel electrochemical studies of ionic liquids," Langmuir, vol. 18, no. 5, pp. 1734-1742, 2002.

[8] T. Welton, "Room temperature ionic liquids: solvents for synthesis and catalysis," Chemical Reviews, vol. 99, no. 8, pp. 2071-2083, 1999.

[9] J. D. Holbrey and K. R. Seddon, "Ionic liquids," Clean Products and Processes, vol. 1, pp. 223-236, 1999.

[10] P. C. Trulove and R. A. Mantz, "Electrochemical properties of ionic liquids," in Ionic Liquids in Synthesis, T. Welton and P. Wasserscheld, Eds., p. 368, John Wiley \& Sons, Morlenbach, Germany, 2003.

[11] S. Gabriel and J. Weiner, "On some derivatives of propylamines," Journal of the American Chemical Society, vol. 21, pp. 2669-2679, 1888.

[12] P. Walden, "Molecular weights and electrical conductivity of several fused salts," Bulletin of the Imperial Academy of Sciences (Saint Petersburg), vol. 1800, pp. 405-422, 1914.

[13] H. L. Chum, V. R. Koch, L. L. Miller, and R. A. Osteryoung, "An electrochemical scrutiny of organometallic iron complexes and hexamethylbenzene in a room temperature molten salt [32]," Journal of the American Chemical Society, vol. 97, no. 11, pp. 3264-3265, 1975.

[14] J. S. Wilkes, J. A. Levisky, R. A. Wilson, and C. L. Hussey, "Dialkylimidazolium chloroaluminate melts: A new class of room-temperature ionic liquids for electrochemistry, spectroscopy, and synthesis," Inorganic Chemistry, vol. 21, no. 3, pp. 1263-1264, 1982.

[15] J. Robinson and R. A. Osteryoung, "An electrochemical and spectroscopic study of some aromatic hydrocarbons in the room temperature molten salt system aluminum chloride-nbutylpyridinium chloride," Journal of the American Chemical Society, vol. 101, no. 2, pp. 323-327, 1979.

[16] T. B. Scheffler, C. L. Hussey, K. R. Seddon, C. M. Kear, and P. D. Armitage, "Molybdenum chloro complexes in roomtemperature chloroaluminate ionic liquids: Stabilization of $\left[\mathrm{MoCl}_{4}\right]_{2}$ - and $\left[\mathrm{MoCl}_{6}\right]_{3}$," Inorganic Chemistry, vol. 22, no. 15, pp. 2099-2100, 1983.

[17] D. Appleby, C. L. Hussey, K. R. Seddon, and J. E. Turp, "Room-temperature ionic liquids as solvents for electronic absorption spectroscopy of halide complexes," Nature, vol. 323, no. 6089, pp. 614-616, 1986.

[18] C. L. Hussey, "Review on ionic liquids," Advances in Molten Salt Chemistry, vol. 5, pp. 185-199, 1983.

[19] R. J. Gale and R. A. Osteryoung, "Potentiometric investigation of dialuminum heptachloride formation in aluminum chloride-1-butylpyridinium chloride mixtures," Inorganic Chemistry, vol. 18, no. 6, pp. 1603-1605, 1979.

[20] J. S. Wilkes and M. J. Zaworotko, "Air and water stable 1ethyl-3-methylimidazolium based ionic liquids," Journal of the Chemical Society, Chemical Communications, no. 13, pp. 965-967, 1992.

[21] J. Dupont, "On the solid, liquid and solution structural organization of imidazolium ionic liquids," Journal of the Brazilian Chemical Society, vol. 15, no. 3, pp. 341-350, 2004.

[22] P. Bonhote, A. P. Dias, N. Papageorgiou, K. Kalyanasundaram, and M. Grätzel, "Hydrophobic, highly conductive ambient-temperature molten salts," Inorganic Chemistry, vol. 35, no. 5, pp. 1168-1178, 1996.

[23] P. C. Trulove, H. C. De Long, G. R. Stafford, and S. Deki, Eds., Molten Salts, The Electrochemical Society Proceedings Series, Pennington, NJ, USA, 1998.

[24] D. R. MacFarlane, P. Meakin, J. Sun, N. Amini, and M. Forsyth, "Pyrrolidinium imides: a new family of molten salts and conductive plastic crystal phases," Journal of Physical Chemistry B, vol. 103, no. 20, pp. 4164-4170, 1999.

[25] R. Renner, "Ionic liquids: an industrial cleanup solution," Environmental Science and Technology, vol. 35, no. 19, 2001.

[26] P. Wasserscheid and W. Keim, "Ionic liquids—new "solutions" for transition metal catalysis," Angewandte ChemieInternational Edition, vol. 39, no. 21, pp. 3773-3789, 2000.

[27] J. Gorman, "Faster, better, cleaner? New liquids take aim at old-fashioned chemistry," Science News, vol. 160, pp. 156158, 2001.

[28] J. F. Brennecke and E. J. Maginn, "Ionic liquids: innovative fluids for chemical processing," AIChE Journal, vol. 47, no. 11, pp. 2384-2389, 2001.

[29] Q. Yang and D. D. Dionysios, "Photolytic degradation of chlorinated phenols in room temperature ionic liquids," Journal of Photochemistry and Photobiology A, vol. 165, no. 1-3, pp. 229-240, 2004.

[30] K. R. Seddon, "Room-temperature ionic liquids: neoteric solvents for clean catalysis," Kinetics and Catalysis, vol. 37, no. 5, pp. 693-697, 1996.

[31] C. Lagrost, D. Carrié, M. Vaultier, and P. Hapiot, "Reactivities of some electrogenerated organic cation radicals in roomtemperature ionic liquids: toward an alternative to volatile organic solvents?" Journal of Physical Chemistry A, vol. 107, no. 5, pp. 745-752, 2003.

[32] A. Shariati and C. J. Peters, "High-pressure phase equilibria of systems with ionic liquids," Journal of Supercritical Fluids, vol. 34, no. 2, pp. 171-176, 2005. 
[33] A. Shariati, K. Gutkowski, and C. J. Peters, "Comparison of the phase behavior of some selected binary systems with ionic liquids," AIChE Journal, vol. 51, no. 5, pp. 1532-1540, 2005.

[34] H. Zhao, S. Xia, and P. Ma, "Review: use of ionic liquids as green solvents for extractions," Journal of Chemical Technology \& Biotechnology, vol. 80, pp. 1089-1096, 2005.

[35] Y. S. Fung and D. R. Zhu, "Electrodeposited tin coating as negative electrode material for lithium-ion battery in room temperature molten salt," Journal of the Electrochemical Society, vol. 149, no. 3, pp. A319-A324, 2002.

[36] H. Shobukawa, H. Tokuda, M. A. B. H. Susan, and M. Watanabe, "Ion transport properties of lithium ionic liquids and their ion gels," Electrochimica Acta, vol. 50, no. 19, pp. 3872-3877, 2005.

[37] H. Shobukawa, H. Tokuda, S. I. Tabata, and M. Watanabe, "Preparation and transport properties of novel lithium ionic liquids," Electrochimica Acta, vol. 50, no. 2-3, pp. 305-309, 2004.

[38] S. Seki, Y. Kobayashi, H. Miyashiro et al., "Highly reversible lithium metal secondary battery using a room temperature ionic liquid/lithium salt mixture and a surface-coated cathode active material," Chemical Communications, no. 5, pp. 544-545, 2006.

[39] J. D. Stenger-Smith, C. K. Webber, N. Anderson, A. P. Chafin, K. Zong, and J. R. Reynolds, "Poly(3,4alkylenedioxythiophene)-based supercapacitors using ionic liquids as supporting electrolytes," Journal of the Electrochemical Society, vol. 149, no. 8, pp. A973-A977, 2002.

[40] T. Sato, G. Masuda, and K. Takagi, "Electrochemical properties of novel ionic liquids for electric double layer capacitor applications," Electrochimica Acta, vol. 49, no. 21, pp. 3603 3611, 2004.

[41] H. Liu, P. He, Z. Li, Y. Liu, and J. Li, "A novel nickelbased mixed rare-earth oxide/activated carbon supercapacitor using room temperature ionic liquid electrolyte," Electrochimica Acta, vol. 51, no. 10, pp. 1925-1931, 2006.

[42] A. Noda, M. A. B. H. Susan, K. Kudo, S. Mitsushima, K. Hayamizu, and M. Watanabe, "Brønsted acid-base ionic liquids as proton-conducting nonaqueous electrolytes," Journal of Physical Chemistry B, vol. 107, no. 17, pp. 4024-4033, 2003.

[43] W. Kubo, K. Murakoshi, T. Kitamura et al., "Quasi-solidstate dye-sensitized $\mathrm{TiO}_{2}$ solar cells: effective charge transport in mesoporous space filled with gel electrolytes containing iodide and iodine," Journal of Physical Chemistry B, vol. 105, no. 51, pp. 12809-12815, 2001.

[44] W. Kubo, T. Kitamura, K. Hanabusa, Y. Wada, and S. Yanagida, "Quasi-solid-state dye-sensitized solar cells using room temperature molten salts and a low molecular weight gelator," Chemical Communications, no. 4, pp. 374-375, 2002.

[45] P. Wang, S. M. Zakeeruddin, J. E. Moser, and M. Grätzel, "A new ionic liquid electrolyte enhances the conversion efficiency of dye-sensitized solar cells," Journal of Physical Chemistry B, vol. 107, no. 48, pp. 13280-13285, 2003.

[46] J. Xia, N. Masaki, K. Jiang, and S. Yanagida, "Deposition of a thin film of TiOx from a titanium metal target as novel blocking layers at conducting glass $/ \mathrm{TiO}_{2}$ interfaces in ionic liquid mesoscopic $\mathrm{TiO}_{2}$ dye-sensitized solar cells," Journal of Physical Chemistry B, vol. 110, no. 50, pp. 25222-25228, 2006.

[47] P. Wang, S. M. Zakeeruddin, J. E. Moser, R. Humphry-Baker, and M. Grätzel, "A solvent-free, $\mathrm{SeCN}^{-} /(\mathrm{SeCN})_{3}^{-}$based ionic liquid electrolyte for high-efficiency dye-sensitized nanocrystalline solar cells," Journal of the American Chemical Society, vol. 126, no. 23, pp. 7164-7165, 2004.
[48] P. Wang, S. M. Zakeeruddin, P. Comte, I. Exnar, and M. Grätzel, "Gelation of ionic liquid-based electrolytes with silica nanoparticles for quasi-solid-state dye-sensitized solar cells," Journal of the American Chemical Society, vol. 125, no. 5, pp. 1166-1167, 2003.

[49] D. Zhou, G. M. Spinks, G. G. Wallace et al., "Solid state actuators based on polypyrrole and polymer-in-ionic liquid electrolytes," Electrochimica Acta, vol. 48, no. 14-16, pp. 2355-2359, 2003.

[50] J. L. Anderson and D. W. Armstrong, "High-stability ionic liquids. A new class of stationary phases for gas chromatography," Analytical Chemistry, vol. 75, no. 18, pp. 4851-4858, 2003.

[51] X. Xiaohua, Z. Liang, L. Xia, and J. Shengxiang, "Ionic liquids as additives in high performance liquid chromatography: analysis of amines and the interaction mechanism of ionic liquids," Analytica Chimica Acta, vol. 519, no. 2, pp. 207-211, 2004.

[52] J. F. Peng, J. F. Liu, X. L. Hu, and G. B. Jiang, "Direct determination of chlorophenols in environmental water samples by hollow fiber supported ionic liquid membrane extraction coupled with high-performance liquid chromatography," Journal of Chromatography A, vol. 1139, no. 2, pp. 165-170, 2007.

[53] S. Qi, S. Cui, Y. Cheng, X. Chen, and Z. Hu, "Rapid separation and determination of aconitine alkaloids in traditional Chinese herbs by capillary electrophoresis using 1-butyl-3-methylimidazoium-based ionic liquid as running electrolyte," Biomedical Chromatography, vol. 20, no. 3, pp. 294-300, 2006.

[54] K. Tian, S. Qi, Y. Cheng, X. Chen, and Z. Hu, "Separation and determination of lignans from seeds of Schisandra species by micellar electrokinetic capillary chromatography using ionic liquid as modifier," Journal of Chromatography A, vol. 1078, no. 1-2, pp. 181-187, 2005.

[55] O. Oter, K. Ertekin, D. Topkaya, and S. Alp, "Room temperature ionic liquids as optical sensor matrix materials for gaseous and dissolved $\mathrm{CO}_{2}$," Sensors and Actuators, $B$, vol. 117, no. 1, pp. 295-301, 2006.

[56] K. A. Fletcher, S. Pandey, I. K. Storey, A. E. Hendricks, and S. Pandey, "Selective fluorescence quenching of polycyclic aromatic hydrocarbons by nitromethane within room temperature ionic liquid 1-butyl-3-methylimidazolium hexafluorophosphate," Analytica Chimica Acta, vol. 453, no. 1, pp. 89-96, 2002.

[57] M. Mank, B. Stahl, and G. Boehm, "2,5-Dihydroxybenzoic acid butylamine and other ionic liquid matrixes for enhanced MALDI-MS analysis of biomolecules," Analytical Chemistry, vol. 76, no. 10, pp. 2938-2950, 2004.

[58] P. C. Trulove and R. A. Mantz, "Chapter 3. Physicochemical properties of ionic liquids," in Ionic Liquids in Synthesis, P. Wasserscheid and T. Welton, Eds., pp. 103-126, John Wiley \& Sons, Weinheim, Germany, 2003.

[59] B. D. Fitchett, T. N. Knepp, and J. C. Conboy, "1-Alkyl-3methylimidazolium bis(perfluoroalkylsulfonyl)imide waterimmiscible ionic liquids: the effect of water on electrochemical and physical properties," Journal of the Electrochemical Society, vol. 151, no. 7, pp. E219-E225, 2004.

[60] H. Weingärtner, P. Sasisanker, C. Daguenet et al., "The dielectric response of room-temperature ionic liquids: effect of cation variation," Journal of Physical Chemistry B, vol. 111, no. 18 , pp. 4775-4780, 2007. 
[61] P. Bonhte, A. P. Dias, N. Papageorgiou, K. Kalyanasundaram, and M. Grätzel, "Hydrophobic, Highly Conductive AmbientTemperature Molten Salts," Inorganic Chemistry, vol. 35, no. 5, pp. 1168-1178, 1996.

[62] P. Trulove and R. Mantz, "Chemical synthesis using supercritical fluids," in Ionic Liquids in synthesis, P. Wasserscheid and T. Welton, Eds., pp. 112-116, Wiley-VCH, Verlag GmbH, 2003.

[63] K. R. Seddon, A. Stark, and M. J. Torres, "Viscosity and density of 1-alkyl-3-methylimidazolium ionic liquids," ACS Symposium Series, vol. 819, pp. 34-49, 2002.

[64] H. T. Evans, CRC Handbook of Chemistry and Physics, Edited by D. R. Lide, CRC Press, Boston, Mass, USA, 75th edition, 1994.

[65] M. C. Buzzeo, R. G. Evans, and R. G. Compton, "Non-haloaluminate room-temperature ionic liquids in electrochemistry-a review," ChemPhysChem, vol. 5, no. 8, pp. 1106-1120, 2004.

[66] J. Jacquemin, P. Husson, A. A. H. Padua, and V. Majer, "Density and viscosity of several pure and water-saturated ionic liquids," Green Chemistry, vol. 8, no. 2, pp. 172-180, 2006.

[67] S. V. Dzyuba and R. A. Bartsch, "Influence of structural variations in 1-alkyl(aralkyl)-3-methylimidazolium hexafluorophosphates and bis(trifluoromethyl-sulfonyl)imides on physical properties of the ionic liquids," ChemPhysChem, vol. 3, no. 2, pp. 161-166, 2002.

[68] A. R. Mantz and P. C. Trulove, "Physicochemical properties of ionic liquids," in Ionic Liquids in Synthesis, P. Wasserscheid and T. Welton, Eds., pp. 75-143, Wiley-VCH, Berlin, Germany, 2003.

[69] J. G. Huddleston, A. E. Visser, W. M. Reichert, H. D. Willauer, G. A. Broker, and R. D. Rogers, "Characterization and comparison of hydrophilic and hydrophobic room temperature ionic liquids incorporating the imidazolium cation," Green Chemistry, vol. 3, no. 4, pp. 156-164, 2001.

[70] M. C. Kroon, W. Buijs, C. J. Peters, and G. J. Witkamp, "Quantum chemical aided prediction of the thermal decomposition mechanisms and temperatures of ionic liquids," Thermochimica Acta, vol. 465, no. 1-2, pp. 40-47, 2007.

[71] P. Bonhte, A. P. Dias, N. Papageorgiou, K. Kalyanasundaram, and M. Grätzel, "Hydrophobic, highly conductive ambienttemperature molten salts," Inorganic Chemistry, vol. 35, no. 5, pp. 1168-1178, 1996.

[72] A. B. McEwen, H. L. Ngo, K. LeCompte, and J. L. Goldman, "Electrochemical properties of imidazolium salt electrolytes for electrochemical capacitor applications," Journal of the Electrochemical Society, vol. 146, no. 5, pp. 1687-1695, 1999.

[73] P. A. Z. Suarez, C. S. Consorti, R. F. De Souza, J. Dupont, and R. S. Gonçalves, "Electrochemical behavior of vitreous glass carbon and platinum electrodes in the ionic liquid 1-nbutyl-3-methylimidazolium trifluoroacetate," Journal of the Brazilian Chemical Society, vol. 13, no. 1, pp. 106-109, 2002.

[74] D. J. Sandman, Handbook of Conducting Polymers, CRC Press, Boca Raton, Fla, USA, 1998.

[75] P. Chandrasekhar, Conducting Polymers, Fundamentals and Applications: A Practical Approach, Kluwer Academic, Boston, Mass, USA, 1999.

[76] G. Sonmez, "Polymeric electrochromics," Chemical Communications, no. 42, pp. 5251-5259, 2005.

[77] G. G. Wallace, G. M. Spinks, L. A. P. Kane-Maguire, and P. R. Teasdale, Conductive Electroactive Polymers: Intelligent Materials Systems, CRC Press, Boca Raton, Fla, USA, 2nd edition, 2003.
[78] H. Shirakawa, E. J. Louis, A. G. MacDiarmid, C. K. Chiang, and A. J. Heeger, "Synthesis of electrically conducting organic polymers: halogen derivatives of polyacetylene, (CH)x," Journal of the Chemical Society, Chemical Communications, no. 16 , pp. 578-580, 1977.

[79] C. K. Chiang, M. A. Druy, S. C. Gau et al., "Synthesis of highly conducting films of derivatives of polyacetylene, $(\mathrm{CH}) \mathrm{x}$," Journal of the American Chemical Society, vol. 100, no. 3, pp. 1013-1015, 1978.

[80] J. Ding, D. Zhou, G. Spinks et al., "Use of ionic liquids as electrolytes in electromechanical actuator systems based on inherently conducting polymers," Chemistry of Materials, vol. 15, no. 12, pp. 2392-2398, 2003.

[81] W. Lu, I. D. Norris, and B. R. Mattes, "Electrochemical actuator devices based on polyaniline yarns and ionic liquid electrolytes," Australian Journal of Chemistry, vol. 58, no. 4, pp. 263-269, 2005.

[82] W. Lu and B. R. Mattes, "Factors influencing electrochemical actuation of polyaniline fibers in ionic liquids," Synthetic Metals, vol. 152, no. 1-3, pp. 53-56, 2005.

[83] W. Lu, A. G. Fadeev, B. Qi et al., "Use of ionic liquids for $\pi$-conjugated polymer electrochemical devices," Science, vol. 297, no. 5583, pp. 983-987, 2002.

[84] D. Zhou, G. M. Spinks, G. G. Wallace et al., "Solid state actuators based on polypyrrole and polymer-in-ionic liquid electrolytes," Electrochimica Acta, vol. 48, no. 14-16, pp. 2355-2359, 2003.

[85] F. Vidal, C. Plesse, H. Randriamahazaka, D. Teyssie, and C. Chevrot, "Long-life air working semi-IPN/ionic liquid: new precursor of artificial muscles," Molecular Crystals and Liquid Crystals, vol. 448, pp. 95-102, 2006.

[86] F. Vidal, C. Plesse, D. Teyssié, and C. Chevrot, "Long-life air working conducting semi-IPN/ionic liquid based actuator," Synthetic Metals, vol. 142, no. 1-3, pp. 287-291, 2004.

[87] B. J. Akle, M. D. Bennett, and D. J. Leo, "High-strain ionomeric-ionic liquid electroactive actuators," Sensors and Actuators, A, vol. 126, no. 1, pp. 173-181, 2006.

[88] T. Fukushima, K. Asaka, A. Kosaka, and T. Aida, "Fully plastic actuator through layer-by-layer casting with ionicliquid-based bucky gel," Angewandte Chemie-International Edition, vol. 44, no. 16, pp. 2410-2413, 2005.

[89] J. D. Stenger-Smith, C. K. Webber, N. Anderson, A. P. Chafin, K. Zong, and J. R. Reynolds, "Poly(3,4alkylenedioxythiophene)-based supercapacitors using ionic liquids as supporting electrolytes," Journal of the Electrochemical Society, vol. 149, no. 8, pp. A973-A977, 2002.

[90] A. Balducci, F. Soavi, and M. Mastragostino, "The use of ionic liquids as solvent-free green electrolytes for hybrid supercapacitors," Applied Physics A, vol. 82, no. 4, pp. 627632, 2006.

[91] A. Balducci, U. Bardi, S. Caporali, M. Mastragostino, and F. Soavi, "Ionic liquids for hybrid supercapacitors," Electrochemistry Communications, vol. 6, no. 6, pp. 566-570, 2004.

[92] W. Lu, A. G. Fadeev, B. Qi, and B. R. Mattes, "Fabricating conducting polymer electrochromic devices using ionic liquids," Journal of the Electrochemical Society, vol. 151, no. 2, pp. H33-H39, 2004.

[93] C. Yang, Q. Sun, T. Qiao, and Y. Li, "Ionic liquid doped polymer light-emitting electrochemical cells," Journal of Physical Chemistry B, vol. 107, no. 47, pp. 12981-12988, 2003.

[94] J. F. Oudard, R. D. Allendoerfer, and R. A. Osteryoung, "Simultaneous EPR electrochemical measurements on polyfluorene in ambient temperature ionic liquids," Synthetic Metals, vol. 22, no. 4, pp. 407-414, 1988. 
[95] L. Janiszewska and R. A. Osteryoung, "Formation and electrochemistry of polyfluorene in ambient temperature ionic liquids," Journal of the Electrochemical Society, vol. 135, no. 1, pp. 116-122, 1988.

[96] L. Janiszewska and R. A. Osteryoung, "Electrochemistry of polythiophene and polybithiophene films in ambient temperature molten salts," Journal of the Electrochemical Society, vol. 134, no. 11, pp. 2787-2793, 1987.

[97] S. A. Arnautov, "Electrochemical synthesis of polyphenylene in a new ionic liquid," Synthetic Metals, vol. 84, no. 1-3, pp. 295-296, 1997.

[98] P. Hapiot and P. Audebert, "Fast electrochemical studies of the polymerization mechanisms of pyrroles and thiophenes. Identification of the first steps. Existence of $\pi$-dimers in solution," Synthetic Metals, vol. 75, no. 2, pp. 95-102, 1995.

[99] A. M. Fenelon and C. B. Breslin, "The formation of polypyrrole at iron from 1-Butyl-3-methylimidazolium hexafluorophosphate," Journal of the Electrochemical Society, vol. 152, no. 1, pp. D6-D11, 2005.

[100] D. L. Boxall and R. A. Osteryoung, "Switching potentials and conductivity of polypyrrole films prepared in the ionic liquid 1-butyl-3-methylimidazolium hexafluorophosphate," Journal of the Electrochemical Society, vol. 151, no. 2, pp. E41E45, 2004.

[101] K. Sekiguchi, M. Atobe, and T. Fuchigami, "Electropolymerization of pyrrole in 1-ethyl-3-methylimidazolium trifluoromethanesulfonate room temperature ionic liquid," Electrochemistry Communications, vol. 4, no. 11, pp. 881-885, 2002.

[102] K. Wagner, J. M. Pringle, S. B. Hall, M. Forsyth, D. R. MacFarlane, and D. L. Officer, "Investigation of the electropolymerisation of EDOT in ionic liquids," Synthetic Metals, vol. 153, no. 1-3, pp. 257-260, 2005.

[103] P. Damlin, C. Kvarnström, and A. Ivaska, "Electrochemical synthesis and in situ spectroelectrochemical characterization of poly(3,4-ethylenedioxythiophene) (PEDOT) in room temperature ionic liquids," Journal of Electroanalytical Chemistry, vol. 570, no. 1, pp. 113-122, 2004.

[104] S. Ahmad, M. Deepa, and S. Singh, "Electrochemical synthesis and surface characterization of poly $(3,4-$ ethylenedioxythiophene) films grown in an ionic liquid," Langmuir, vol. 23, no. 23, pp. 11430-11433, 2007.

[105] E. Naudin, H. A. Ho, S. Branchaud, L. Breau, and D. Bélanger, "Electrochemical polymerization and characterization of poly(3-(4-fluorophenyl)thiophene) in pure ionic liquids," Journal of Physical Chemistry B, vol. 106, no. 41, pp. 1058510593, 2002.

[106] S. Z. El Abedin, N. Borissenko, and F. Endres, "Electropolymerization of benzene in a room temperature ionic liquid," Electrochemistry Communications, vol. 6, no. 4, pp. 422-426, 2004.

[107] Y. Pang, H. Xu, X. Li et al., "Electrochemical synthesis, characterization, and electrochromic properties of poly(3chlorothiophene) and its copolymer with 3-methylthiophene in a room temperature ionic liquid," Electrochemistry Communications, vol. 8, no. 11, pp. 1757-1763, 2006.

[108] J. M. Pringle, M. Forsyth, D. R. MacFarlane, K. Wagner, S. B. Hall, and D. L. Officer, "The influence of the monomer and the ionic liquid on the electrochemical preparation of polythiophene," Polymer, vol. 46, no. 7, pp. 2047-2058, 2005.

[109] W. Lu, A. G. Fadeev, B. Qi et al., "Use of ionic liquids for $\pi$-conjugated polymer electrochemical devices," Science, vol. 297, no. 5583, pp. 983-987, 2002.
[110] K. Sekiguchi, M. Atobe, and T. Fuchigami, "Electropolymerization of pyrrole in 1-ethyl-3-methylimidazolium trifluoromethanesulfonate room temperature ionic liquid," Electrochemistry Communications, vol. 4, no. 11, pp. 881-885, 2002.

[111] S. Z. El Abedin, N. Borissenko, and F. Endres, "Electropolymerization of benzene in a room temperature ionic liquid," Electrochemistry Communications, vol. 6, no. 4, pp. 422-426, 2004.

[112] J. M. Pringle, J. Efthimiadis, P. C. Howlett et al., "Electrochemical synthesis of polypyrrole in ionic liquids," Polymer, vol. 45, no. 5, pp. 1447-1453, 2004.

[113] K. Sekiguchi, M. Atobe, and T. Fuchigami, "Electrooxidative polymerization of aromatic compounds in 1-ethyl-3methylimidazolium trifluoromethanesulfonate roomtemperature ionic liquid," Journal of Electroanalytical Chemistry, vol. 557, pp. 1-7, 2003.

[114] K. Wagner, J. M. Pringle, S. B. Hall, M. Forsyth, D. R. MacFarlane, and D. L. Officer, "Investigation of the electropolymerisation of EDOT in ionic liquids," Synthetic Metals, vol. 153, no. 1-3, pp. 257-260, 2005.

[115] B. Y. Liu, D. Q. Xu, and Z. Y. Xu, "Electrochemical synthesis of dendritic polyaniline in brønsted acid ionic liquids," Chinese Journal of Chemistry, vol. 23, no. 7, pp. 803-805, 2005.

[116] M. C. Li, C. A. Ma, B. Y. Liu, and Z. M. Jin, "A novel electrolyte 1-ethylimidazolium trifluoroacetate used for electropolymerization of aniline," Electrochemistry Communications, vol. 7, no. 2, pp. 209-212, 2005.

[117] B. Dong, L. Zheng, J. Xu, H. Liu, and S. Pu, "Electropolymerization of 1,2-methylenedioxybenzene in 1-butyl3-methylimidazolium hexafluorophosphate room temperature ionic liquid," Polymer, vol. 48, no. 19, pp. 5548-5555, 2007.

[118] K. Sekiguchi, M. Atobe, and T. Fuchigami, "Electropolymerization of pyrrole in 1-ethyl-3-methylimidazolium trifluoromethanesulfonate room temperature ionic liquid," Electrochemistry Communications, vol. 4, no. 11, pp. 881-885, 2002.

[119] J. M. Pringle, J. Efthimiadis, P. C. Howlett et al., "Electrochemical synthesis of polypyrrole in ionic liquids," Polymer, vol. 45, no. 5, pp. 1447-1453, 2004.

[120] J. M. Pringle, M. Forsyth, G. G. Wallace, and D. R. MacFarlane, "Solution-surface electropolymerization: a route to morphologically novel poly(pyrrole) using an ionic liquid," Macromolecules, vol. 39, no. 21, pp. 7193-7195, 2006.

[121] J. M. Pringle, O. Ngamna, C. Lynam, G. G. Wallace, M. Forsyth, and D. R. MacFarlane, "Conducting polymers with fibrillar morphology synthesized in a biphasic ionic liquid/water system," Macromolecules, vol. 40, no. 8, pp. 2702-2711, 2007.

[122] Q. Kang, L. Yang, and Q. Cai, "An electro-catalytic biosensor fabricated with Pt-Au nanoparticle-decorated titania nanotube array," Bioelectrochemistry, vol. 74, no. 1, pp. 62-65, 2008.

[123] F. Xiao, F. Zhao, J. Li, L. Liu, and B. Zeng, "Characterization of hydrophobic ionic liquid-carbon nanotubesgold nanoparticles composite film coated electrode and the simultaneous voltammetric determination of guanine and adenine," Electrochimica Acta, vol. 53, no. 26, pp. 7781-7788, 2008.

[124] C. Hardacre, J. D. Holbrey, S. E. J. McMath, D. T. Bowron, and A. K. Soper, "Structure of molten 1,3dimethylimidazolium chloride using neutron diffraction," 
Journal of Chemical Physics, vol. 118, no. 1, pp. 273-278, 2003.

[125] S. Tsuzuki, H. Tokuda, K. Hayamizu, and M. Watanabe, "Magnitude and directionality of interaction in ion pairs of ionic liquids: relationship with ionic conductivity," Journal of Physical Chemistry B, vol. 109, no. 34, pp. 16474-16481, 2005.

[126] J. Dupont and P. A. Z. Suarez, "Physico-chemical processes in imidazolium ionic liquids," Physical Chemistry Chemical Physics, vol. 8, no. 21, pp. 2441-2452, 2006.

[127] A. Pearson, A. P. O'Mullane, V. Bansal, and S. K. Bhargava, "Galvanic replacement mediated transformation of Ag nanospheres into dendritic $\mathrm{Au}-\mathrm{Ag}$ nanostructures in the ionic liquid [BMIM] $\left[\mathrm{BF}_{4}\right]$," Chemical Communications, vol. 46, no. 5, pp. 731-733, 2010.

[128] F. Endres, "Ionic liquids: solvents for the electrodeposition of metals and semiconductors," ChemPhysChem, vol. 3, no. 2, pp. 144-154, 2002.

[129] M. Antonietti, D. Kuang, B. Smarsly, and Y. Zhou, "Ionic liquids for the convenient synthesis of functional nanoparticles and other inorganic nanostructures," Angewandte ChemieInternational Edition, vol. 43, no. 38, pp. 4988-4992, 2004.

[130] S. K. Soni, R. Ramanathan, P. J. Coloe, V. Bansal, and S. K. Bhargava, "Self-assembled enzyme capsules in ionic liquid [BMIM] $\left[\mathrm{BF}_{4}\right]$ as templating nanoreactors for hollow silica nanocontainers," Langmuir, vol. 26, no. 20, pp. 16020-16024, 2010.

[131] P. A. Z. Suarez, S. Einloft, J. E. L. Dullius, R. F. De Souza, and J. Dupont, "Synthesis and physical-chemical properties of ionic liquids based on 1-n-butyl-3-methylimidazolium cation," Journal de Chimie Physique et de Physico-Chimie Biologique, vol. 95, no. 7, pp. 1626-1639, 1998.

[132] B. A. DaSilveira Neto, L. S. Santos, F. M. Nachtigall, M. N. Eberlin, and J. Dupont, "On the species involved in the vaporization of imidazolium ionic liquids in a steamdistillation-like process," Angewandte Chemie-International Edition, vol. 45, no. 43, pp. 7251-7254, 2006.

[133] J. N. A. Canongia Lopes and A. A. H. Pádua, "Nanostructural organization in ionic liquids," Journal of Physical Chemistry $B$, vol. 110, no. 7, pp. 3330-3335, 2006.

[134] M. A. Neouze, "About the interactions between nanoparticles and imidazolium moieties: emergence of original hybrid materials," Journal of Materials Chemistry, vol. 20, no. 43, pp. 9593-9607, 2010.

[135] L. S. Ott and R. G. Finke, "Transition-metal nanocluster stabilization for catalysis: a critical review of ranking methods and putative stabilizers," Coordination Chemistry Reviews, vol. 251, no. 9-10, pp. 1075-1100, 2007.

[136] R. Wang, T. Okajima, F. Kitamura, and T. Ohsaka, "A novel amperometric $\mathrm{O}_{2}$ gas sensor based on supported roomtemperature ionic liquid porous polyethylene membranecoated electrodes," Electroanalysis, vol. 16, no. 1-2, pp. 66-72, 2004.

[137] M. C. Buzzeo, R. G. Evans, and R. G. Compton, "Non-haloaluminate room-temperature ionic liquids in electrochemistry-a review," ChemPhysChem, vol. 5, no. 8, pp. 1106-1120, 2004.

[138] I. M. AlNashef, M. L. Leonard, M. A. Matthews, and J. W. Weidner, "Superoxide electrochemistry in an ionic liquid," Industrial and Engineering Chemistry Research, vol. 41, no. 18, pp. 4475-4478, 2002.

[139] M. C. Buzzeo, O. V. Klymenko, J. D. Wadhawan, C. Hardacre, K. R. Seddon, and R. G. Compton, "Voltammetry of oxygen in the room-temperature ionic liquids 1-ethyl-3-methylimidazolium bis((trifluoromethyl)sulfonyl) imide and hexyltriethylammonium bis((trifluoromethyl) sulfonyl)imide: one-electron reduction to form superoxide. Steady-state and transient behavior in the same cyclic voltammogram resulting from widely different diffusion coefficients of oxygen and superoxide," Journal of Physical Chemistry A, vol. 107, no. 42, pp. 8872-8878, 2003.

[140] M. C. Buzzeo, O. V. Klymenko, J. D. Wadhawan, C. Hardacre, K. R. Seddon, and R. G. Compton, "Kinetic Analysis of the Reaction between Electrogenerated Superoxide and Carbon Dioxide in the Room Temperature Ionic Liquids 1-Ethyl-3-methylimidazolium Bis(trifluoromethylsulfonyl)imide and Hexyltriethylammonium Bis(trifluoromethylsulfonyl)imide," Journal of Physical Chemistry B, vol. 108, no. 12, pp. 3947-3954, 2004.

[141] D. Giovanelli, M. C. Buzzeo, N. S. Lawrence, C. Hardacre, K. R. Seddon, and R. G. Compton, "Determination of ammonia based on the electro-oxidation of hydroquinone in dimethylformamide or in the room temperature ionic liquid, 1-ethyl3- methylimidazolium bis(trifluoromethylsulfonyl)imide," Talanta, vol. 62, no. 5, pp. 904-911, 2004.

[142] M. C. Buzzeo, C. Hardacre, and R. G. Compton, "Use of room temperature ionic liquids in gas sensor design," Analytical Chemistry, vol. 76, no. 15, pp. 4583-4588, 2004.

[143] Q. Cai, Y. Xian, H. Li, T. Yang-ming, and T. Jin, "Studies on a sulfur dioxide electrochemical sensor with ionic liquid as electrolyte," Huadong Shifan Daxue Xuebao, vol. 3, pp. 57-60, 2001.

[144] R. Wang, S. Hoyano, and T. Ohsaka, "O ${ }_{2}$ gas sensor using supported hydrophobic room-temperature ionic liquid membrane-coated electrode," Chemistry Letters, vol. 33, no. 1, pp. 6-7, 2004.

[145] C. Villagrán, C. E. Banks, C. Hardacre, and R. G. Compton, "Electroanalytical determination of trace chloride in roomtemperature ionic liquids," Analytical Chemistry, vol. 76, no. 7, pp. 1998-2003, 2004.

[146] H. Sun, L. Yu, X. Jin, X. Hu, D. Wang, and G. Z. Chen, "Unusual anodic behaviour of chloride ion in 1-butyl-3methylimidazolium hexafluorophosphate," Electrochemistry Communications, vol. 7, no. 7, pp. 685-691, 2005.

[147] L. Aldous, D. S. Silvester, C. Villagrán et al., "Electrochemical studies of gold and chloride in ionic liquids," New Journal of Chemistry, vol. 30, no. 11, pp. 1576-1583, 2006.

[148] T. L. Broder, D. S. Silvester, L. Aldous, C. Hardacre, and R. G. Compton, "Electrochemical oxidation of nitrite and the oxidation and reduction of $\mathrm{NO}_{2}$ in the room temperature ionic liquid $\left[\mathrm{C}_{2} \mathrm{mim}\right]\left[\mathrm{NTf}_{2}\right]$," Journal of Physical Chemistry B, vol. 111, no. 27, pp. 7778-7785, 2007.

[149] J. L. Anthony, E. J. Maginn, and J. F. Brennecke, "Solubilities and thermodynamic properties of gases in the ionic liquid 1-n-butyl-3-methylimidazolium hexafluorophosphate," Journal of Physical Chemistry B, vol. 106, no. 29, pp. 73157320, 2002.

[150] C. Liang, C. Y. Yuan, R. J. Warmack, C. E. Barnes, and S. Dai, "Ionic liquids: a new class of sensing materials for detection of organic vapors based on the use of a quartz crystal microbalance," Analytical Chemistry, vol. 74, no. 9, pp. 2172-2176, 2002.

[151] X. Jin, L. Yu, D. Garcia, R. X. Ren, and X. Zeng, "Ionic liquid high-temperature gas sensor array," Analytical Chemistry, vol. 78, no. 19, pp. 6980-6989, 2006.

[152] I. Goubaidoulline, G. Vidrich, and D. Johannsmann, "Organic vapor sensing with ionic liquids entrapped in 
alumina nanopores on quartz crystal resonators," Analytical Chemistry, vol. 77, no. 2, pp. 615-619, 2005.

[153] L. Yu, Y. Huang, X. Jin, A. J. Mason, and X. Zeng, "Ionic liquid thin layer EQCM explosives sensor," Sensors and Actuators, B, vol. 140, no. 2, pp. 363-370, 2009.

[154] T. Schäfer, F. Di Francesco, and R. Fuoco, "Ionic liquids as selective depositions on quartz crystal microbalances for artificial olfactory systems-a feasibility study," Microchemical Journal, vol. 85, no. 1, pp. 52-56, 2007.

[155] Y. Zhao, Y. Gao, D. Zhan et al., "Selective detection of dopamine in the presence of ascorbic acid and uric acid by a carbon nanotubes-ionic liquid gel modified electrode," Talanta, vol. 66, no. 1, pp. 51-57, 2005.

[156] W. Tao, D. Pan, Q. Liu, S. Yao, Z. Nie, and B. Han, "Optical and bioelectrochemical characterization of water-miscible ionic liquids based composites of multiwalled carbon nanotubes," Electroanalysis, vol. 18, no. 17, pp. 1681-1688, 2006.

[157] Y. Liu, L. Liu, and S. Dong, "Electrochemical characteristics of glucose oxidase adsorbed at carbon nanotubes modified electrode with ionic liquid as binder," Electroanalysis, vol. 19, no. 1, pp. 55-59, 2007.

[158] Y. Liu, X. Zou, and S. Dong, "Electrochemical characteristics of facile prepared carbon nanotubes-ionic liquid gel modified microelectrode and application in bioelectrochemistry," Electrochemistry Communications, vol. 8, no. 9, pp. 14291434, 2006.

[159] J. Li, L. Liu, R. Yan et al., "Enhanced direct electron transfer reactivity of hemoglobin in cationic gemini surfactant-room temperature ionic liquid composite film on glassy carbon electrodes," Electrochimica Acta, vol. 53, no. 13, pp. 45914598, 2008.

[160] J. Zheng, Y. Zhang, and P. Yang, "An ionic liquid-type carbon paste electrode for electrochemical investigation and determination of calcium dobesilate," Talanta, vol. 73, no. 5, pp. 920-925, 2007.

[161] Y. Liu, L. Huang, and S. Dong, "Electrochemical catalysis and thermal stability characterization of laccase-carbon nanotubes-ionic liquid nanocomposite modified graphite electrode," Biosensors and Bioelectronics, vol. 23, no. 1, pp. 35-41, 2007.

[162] Q. Wang, H. Tang, Q. Xie et al., "Room-temperature ionic liquids/multi-walled carbon nanotubes/chitosan composite electrode for electrochemical analysis of NADH," Electrochimica Acta, vol. 52, no. 24, pp. 6630-6637, 2007.

[163] S. F. Ding, W. Wei, and G. C. Zhao, "Direct electrochemical response of cytochrome $\mathrm{c}$ on a room temperature ionic liquid, N-butylpyridinium tetrafluoroborate, modified electrode," Electrochemistry Communications, vol. 9, no. 9, pp. 2202-2206, 2007.

[164] G. Shul, J. Sirieix-Plenet, L. Gaillon, and M. Opallo, "Ion transfer at carbon paste electrode based on ionic liquid," Electrochemistry Communications, vol. 8, no. 7, pp. 11111114, 2006.

[165] X. Lu, J. Hu, X. Yao, Z. Wang, and J. Li, "Composite system based on chitosan and room-temperature ionic liquid: direct electrochemistry and electrocatalysis of hemoglobin," Biomacromolecules, vol. 7, no. 3, pp. 975-980, 2006.

[166] N. Maleki, A. Safavi, F. Sedaghati, and F. Tajabadi, "Efficient electrocatalysis of 1-cysteine oxidation at carbon ionic liquid electrode," Analytical Biochemistry, vol. 369, no. 2, pp. 149153, 2007.

[167] A. Safavi, N. Maleki, O. Moradlou, and M. Sorouri, "Direct electrochemistry of hemoglobin and its electrocatalytic effect based on its direct immobilization on carbon ionic liquid electrode," Electrochemistry Communications, vol. 10, no. 3, pp. 420-423, 2008.

[168] A. Safavi, N. Maleki, O. Moradlou, and F. Tajabadi, "Simultaneous determination of dopamine, ascorbic acid, and uric acid using carbon ionic liquid electrode," Analytical Biochemistry, vol. 359, no. 2, pp. 224-229, 2006.

[169] W. Sun, D. Wang, R. Gao, and K. Jiao, "Direct electrochemistry and electrocatalysis of hemoglobin in sodium alginate film on a $\mathrm{BMIMPF}_{6}$ modified carbon paste electrode," Electrochemistry Communications, vol. 9, no. 5, pp. 11591164, 2007.

[170] W. Sun, R. Gao, and K. Jiao, "Electrochemistry and electrocatalysis of hemoglobin in nafion/nano- $\mathrm{CaCO}_{3}$ film on a new ionic liquid $\mathrm{BPPF}_{6}$ modified carbon paste electrode," Journal of Physical Chemistry B, vol. 111, no. 17, pp. 45604567, 2007.

[171] W. Sun, R. F. Gao, and K. Jiao, "Electrochemistry and electrocatalysis of a Nafion/Nano- $\mathrm{CaCO}_{3} / \mathrm{Hb}$ film modified carbon ionic liquid electrode using $\mathrm{BMIMPF}_{6}$ as binder," Electroanalysis, vol. 19, no. 13, pp. 1368-1374, 2007.

[172] W. Sun, Q. Jiang, Y. Wang, and K. Jiao, "Electrochemical behaviors of metol on hydrophilic ionic liquid 1-ethyl-3methylimidazolium tetrafluoroborate-modified electrode," Sensors and Actuators, B, vol. 136, no. 2, pp. 419-424, 2009.

[173] F. Xiao, F. Zhao, D. Mei, Z. Mo, and B. Zeng, "Nonenzymatic glucose sensor based on ultrasonic-electrodeposition of bimetallic PtM ( $\mathrm{M}=\mathrm{Ru}, \mathrm{Pd}$ and $\mathrm{Au})$ nanoparticles on carbon nanotubes-ionic liquid composite film," Biosensors and Bioelectronics, vol. 24, no. 12, pp. 3481-3486, 2009.

[174] M. A. Jabbar, H. Shimakoshi, and Y. Hisaeda, "Enhanced reactivity of hydrophobic vitamin B12 towards the dechlorination of DDT in ionic liquid," Chemical Communications, no. 16, pp. 1653-1655, 2007.

[175] S. F. Ding, M. Q. Xu, G. C. Zhao, and X. W. Wei, "Direct electrochemical response of Myoglobin using a room temperature ionic liquid, 1-(2-hydroxyethyl)-3-methyl imidazolium tetrafluoroborate, as supporting electrolyte," Electrochemistry Communications, vol. 9, no. 2, pp. 216-220, 2007.

[176] W. Tu, J. Lei, and H. Ju, "Functionalization of carbon nanotubes with water-insoluble porphyrin in ionic liquid: direct electrochemistry and highly sensitive amperometric biosensing for trichloroacetic acid," Chemistry, vol. 15, no. 3, pp. 779-784, 2009.

[177] V. V. Singh, M. Boopathi, K. Ganesan, B. Singh, and R. Vijayaraghavan, "Ionic liquid as an alternative greener sensing medium for the chemical warfare agent," Electroanalysis, vol. 22, no. 12, pp. 1357-1363, 2010.

[178] M. K. Gupta, S. K. Khokhar, D. M. Phillips et al., "Patterned silk films cast from ionic liquid solubilized fibroin as scaffolds for cell growth," Langmuir, vol. 23, no. 3, pp. 1315-1319, 2007.

[179] J. A. Laszlo and D. L. Compton, "Comparison of peroxidase activities of hemin, cytochrome $\mathrm{c}$ and microperoxidase-11 in molecular solvents and imidazolium-based ionic liquids," Journal of Molecular Catalysis B, vol. 18, no. 1-3, pp. 109-120, 2002.

[180] P. Lozano, T. De Diego, J. P. Guegan, M. Vaultier, and J. L. Iborra, "Stabilization of $\alpha$-chymotrypsin by ionic liquids in transesterification reactions," Biotechnology and Bioengineering, vol. 75, no. 5, pp. 563-569, 2001.

[181] M. Persson and U. T. Bornscheuer, "Increased stability of an esterase from Bacillus stearothermophilus in ionic liquids as 
compared to organic solvents," Journal of Molecular Catalysis B, vol. 22, no. 1-2, pp. 21-27, 2003.

[182] S. N. Baker, T. M. McCleskey, S. Pandey, and G. A. Baker, "Fluorescence studies of protein thermostability in ionic liquids," Chemical Communications, vol. 10, no. 8, pp. 940 941, 2004.

[183] Y. Liu, M. Wang, J. Li et al., "Highly active horseradish peroxidase immobilized in 1-butyl-3- methylimidazolium tetrafluoroborate room-temperature ionic liquid based solgel host materials," Chemical Communications, no. 13, pp. 1778-1780, 2005.

[184] Y. Liu, L. Shi, M. Wang, Z. Li, H. Liu, and J. Li, "A novel room temperature ionic liquid sol-gel matrix for amperometric biosensor application," Green Chemistry, vol. 7, no. 9, pp. 655-658, 2005.

[185] D. L. Compton and J. A. Laszlo, "Direct electrochemical reduction of hemin in imidazolium-based ionic liquids," Journal of Electroanalytical Chemistry, vol. 520, no. 1-2, pp. 71-78, 2002.

[186] S. F. Wang, T. Chen, Z. L. Zhang et al., "Direct electrochemistry and electrocatalysis of heme proteins entrapped in agarose hydrogel films in room-temperature ionic liquids," Langmuir, vol. 21, no. 20, pp. 9260-9266, 2005.

[187] Y. Liu, L. Shi, M. Wang, Z. Li, H. Liu, and J. Li, "A novel room temperature ionic liquid sol-gel matrix for amperometric biosensor application," Green Chemistry, vol. 7, no. 9, pp. 655-658, 2005.

[188] S. F. Ding, M. Q. Xu, G. C. Zhao, and X. W. Wei, "Direct electrochemical response of Myoglobin using a room temperature ionic liquid, 1-(2-hydroxyethyl)-3-methyl imidazolium tetrafluoroborate, as supporting electrolyte," Electrochemistry Communications, vol. 9, no. 2, pp. 216-220, 2007.

[189] R. T. Kachoosangi, G. G. Wildgoose, and R. G. Compton, "Room temperature ionic liquid carbon nanotube paste electrodes: overcoming large capacitive currents using rotating disk electrodes," Electroanalysis, vol. 19, no. 14, pp. 14831489, 2007.

[190] M. Javanbakht, M. R. Ganjali, P. Norouzi, A. Badiei, A. Hasheminasab, and M. Abdouss, "Carbon paste electrode modified with functionalized nanoporous silica gel as a new sensor for determination of silver ion," Electroanalysis, vol. 19, no. 12, pp. 1307-1314, 2007.

[191] M. R. Ganjali, N. Motakef-Kazemi, P. Norouzi, and S. Khoee, "A modified $\mathrm{Ho}^{3+}$ carbon paste electrode based on multi-walled carbon nanotubes (MWCNTS) and nanosilica," International Journal of Electrochemical Science, vol. 4, no. 7, pp. 906-913, 2009.

[192] M. R. Ganjali, N. Motakef-Kazami, F. Faridbod, S. Khoee, and $\mathrm{P}$. Norouzi, "Determination of $\mathrm{Pb} 2+$ ions by a modified carbon paste electrode based on multi-walled carbon nanotubes (MWCNTs) and nanosilica," Journal of Hazardous Materials, vol. 173, no. 1-3, pp. 415-419, 2010.

[193] P. Norouzi, Z. Rafiei-Sarmazdeh, F. Faridbod, M. Adibi, and M. R. Ganjali, " $3+$ carbon paste electrode based on new nanocomposite," International Journal of Electrochemical Science, vol. 5, no. 3, pp. 367-376, 2010.

[194] M. Musameh and J. Wang, "Sensitive and stable amperometric measurements at ionic liquid-carbon paste microelectrodes," Analytica Chimica Acta, vol. 606, no. 1, pp. 45-49, 2008.

[195] E. Rapp, A. Charvát, A. Beinsen et al., "Atmospheric pressure free liquid infrared MALDI mass spectrometry: toward a combined ESI/MALDI-liquid chromatography interface," Analytical Chemistry, vol. 81, no. 1, pp. 443-452, 2009.

[196] Q. Wang, H. Tang, Q. Xie et al., "Room-temperature ionic liquids/multi-walled carbon nanotubes/chitosan composite electrode for electrochemical analysis of NADH," Electrochimica Acta, vol. 52, no. 24, pp. 6630-6637, 2007.

[197] F. Zhao, X. Wu, M. Wang, Y. Liu, L. Gao, and S. Dong, "Electrochemical and bioelectrochemistry properties of roomtemperature ionic liquids and carbon composite materials," Analytical Chemistry, vol. 76, no. 17, pp. 4960-4967, 2004.

[198] T. Fukushima, A. Kosaka, Y. Ishimura et al., "Molecular ordering of organic molten salts triggered by single-walled carbon nanotubes," Science, vol. 300, no. 5628, pp. 20722074, 2003.

[199] J. Wang, R. P. Deo, and M. Musameh, "Stable and sensitive electrochemical detection of phenolic compounds at carbon nanotube modified glassy carbon electrodes," Electroanalysis, vol. 15, no. 23-24, pp. 1830-1834, 2003.

[200] K. Wu, J. Fei, and S. Hu, "Simultaneous determination of dopamine and serotonin on a glassy carbon electrode coated with a film of carbon nanotubes," Analytical Biochemistry, vol. 318, no. 1, pp. 100-106, 2003.

[201] Z. Wang, J. Liu, Q. Liang, Y. Wang, and G. Luo, "Carbon nanotube-modified electrodes for the simultaneous determination of dopamine and ascorbic acid," Analyst, vol. 127, no. 5, pp. 653-658, 2002.

[202] M. Musameh, J. Wang, A. Merkoci, and Y. Lin, "Lowpotential stable NADH detection at carbon-nanotubemodified glassy carbon electrodes," Electrochemistry Communications, vol. 4, no. 10, pp. 743-746, 2002.

[203] M. Zhang, K. Gong, H. Zhang, and L. Mao, "Layer-by-layer assembled carbon nanotubes for selective determination of dopamine in the presence of ascorbic acid," Biosensors and Bioelectronics, vol. 20, no. 7, pp. 1270-1276, 2005.

[204] T. Fukushima, A. Kosaka, Y. Ishimura et al., "Molecular ordering of organic molten salts triggered by single-walled carbon nanotubes," Science, vol. 300, no. 5628, pp. 20722074, 2003.

[205] Y. Zhang, Y. Shen, J. Li, L. Niu, S. Dong, and A. Ivaska, "Electrochemical functionalization of single-walled carbon nanotubes in large quantities at a room-temperature ionic liquid supported three-dimensional network electrode," Langmuir, vol. 21, no. 11, pp. 4797-4800, 2005.

[206] J. Zhang, J. Lei, Y. Liu, J. Zhao, and H. Ju, "Highly sensitive amperometric biosensors for phenols based on polyanilineionic liquid-carbon nanofiber composite," Biosensors and Bioelectronics, vol. 24, no. 7, pp. 1858-1863, 2009.

[207] A. I. Gopalan, K. P. Lee, and D. Ragupathy, "Development of a stable cholesterol biosensor based on multi-walled carbon nanotubes-gold nanoparticles composite covered with a layer of chitosan-room-temperature ionic liquid network," Biosensors and Bioelectronics, vol. 24, no. 7, pp. 2211-2217, 2009.

[208] H. Chen, Y. Wang, Y. Liu, Y. Wang, L. Qi, and S. Dong, "Direct electrochemistry and electrocatalysis of horseradish peroxidase immobilized in Nafion-RTIL composite film," Electrochemistry Communications, vol. 9, no. 3, pp. 469-474, 2007.

[209] B. G. Choi, H. Park, T. J. Park, D. H. Kim, S. Y. Lee, and W. H. Hong, "Development of the electrochemical biosensor for organophosphate chemicals using CNT/ionic liquid bucky gel electrode," Electrochemistry Communications, vol. 11, no. 3, pp. 672-675, 2009. 
[210] N. Sun, L. Guan, Z. Shi et al., "Ferrocene peapod modified electrodes: preparation, characterization, and mediation of $\mathrm{H}_{2} \mathrm{O}_{2}$," Analytical Chemistry, vol. 78, no. 17, pp. 6050-6057, 2006.

[211] P. Rahimi, H. A. Rafiee-Pour, H. Ghourchian, P. Norouzi, and M. R. Ganjali, "Ionic-liquid/ $\mathrm{NH}_{2}$-MWCNTs as a highly sensitive nano-composite for catalase direct electrochemistry," Biosensors and Bioelectronics, vol. 25, no. 6, pp. 1301-1306, 2010.

[212] K. S. Novoselov, A. K. Geim, S. V. Morozov et al., "Electric field in atomically thin carbon films," Science, vol. 306, no. 5696, pp. 666-669, 2004

[213] K. I. Bolotin, K. J. Sikes, Z. Jiang et al., "Ultrahigh electron mobility in suspended graphene," Solid State Communications, vol. 146, no. 9-10, pp. 351-355, 2008.

[214] A. K. Geim and K. S. Novoselov, "The rise of graphene," Nature Materials, vol. 6, no. 3, pp. 183-191, 2007.

[215] C. Lee, X. Wei, J. W. Kysar, and J. Hone, "Measurement of the elastic properties and intrinsic strength of monolayer graphene," Science, vol. 321, no. 5887, pp. 385-388, 2008.

[216] H. Yang, C. Shan, F. Li, D. Han, Q. Zhang, and L. $\mathrm{Niu}$, "Covalent functionalization of polydisperse chemicallyconverted graphene sheets with amine-terminated ionic liquid," Chemical Communications, no. 26, pp. 3880-3882, 2009.

[217] C. Shan, H. Yang, J. Song, D. Han, A. Ivaska, and L. Niu, "Direct electrochemistry of glucose oxidase and biosensing for glucose based on graphene," Analytical Chemistry, vol. 81, no. 6, pp. 2378-2382, 2009.

[218] C. Shan, H. Yang, D. Han, Q. Zhang, A. Ivaska, and L. $\mathrm{Niu}$, "Electrochemical determination of NADH and ethanol based on ionic liquid-functionalized graphene," Biosensors and Bioelectronics, vol. 25, no. 6, pp. 1504-1508, 2010.

[219] I. M. Du, T. Yang, S. Y. Ma, C. Z. Zhao, and K. Jiao, "Ionic liquid-functionalized graphene as modifier for electrochemical and electrocatalytic improvement: comparison of different carbon electrodes," Analytica Chimica Acta, vol. 690, pp. 169-174, 2011. 


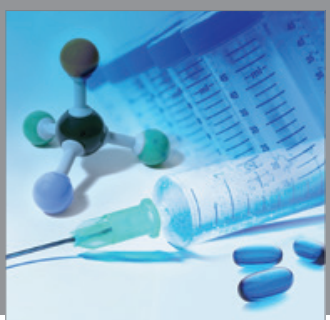

International Journal of

Medicinal Chemistry

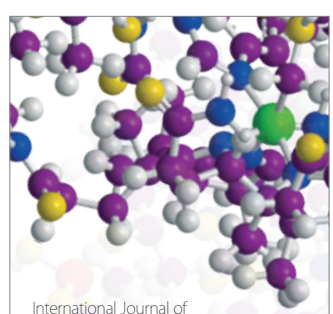

Carbohydrate Chemistry

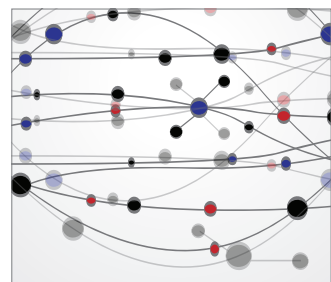

The Scientific World Journal
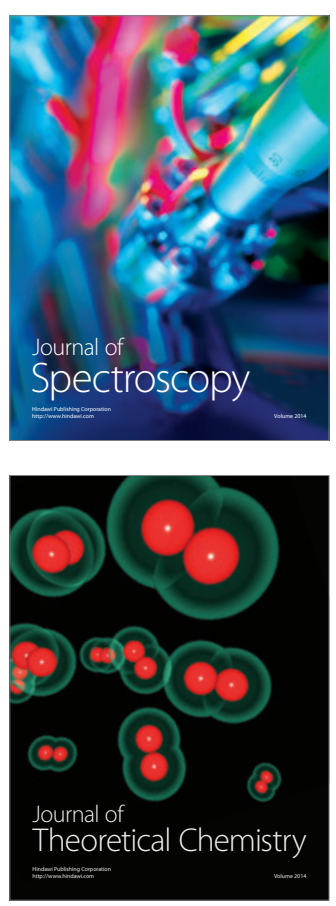
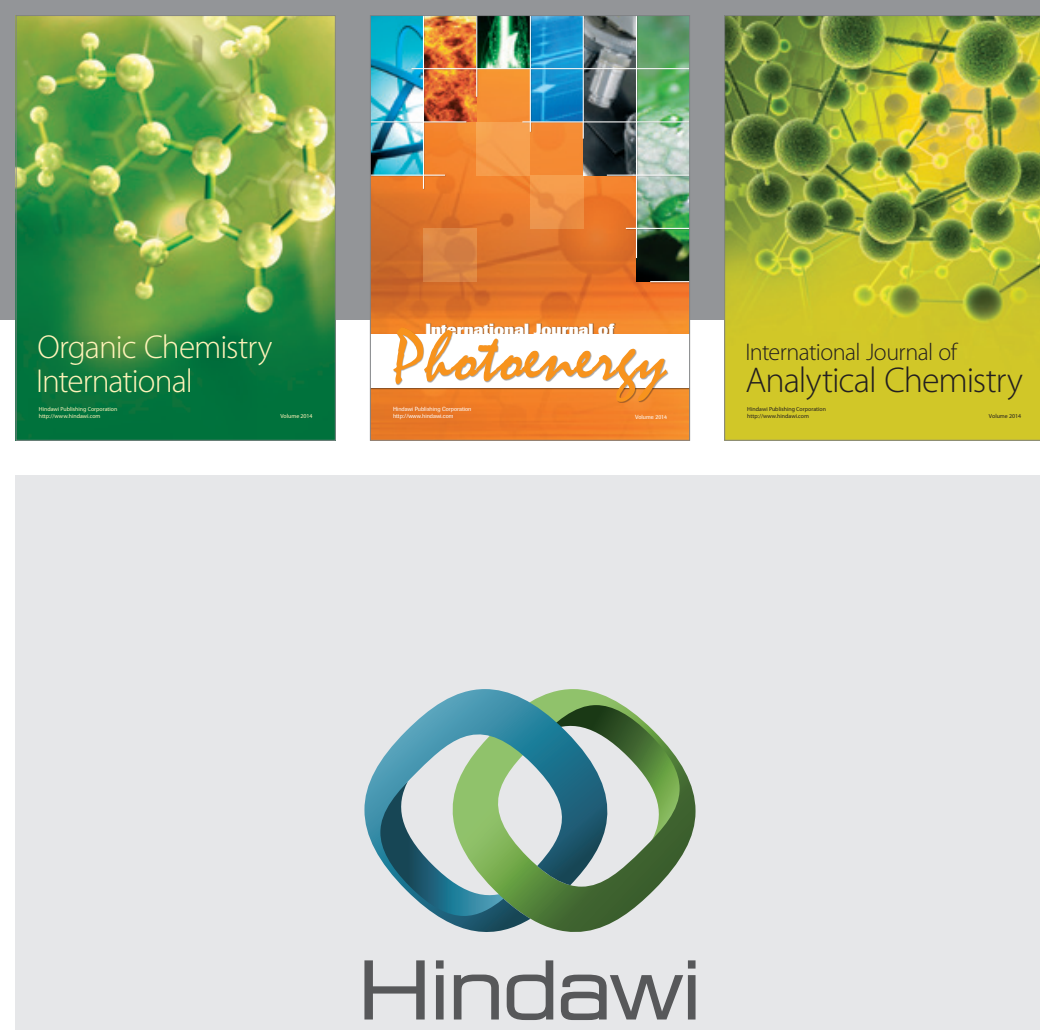

Submit your manuscripts at

http://www.hindawi.com
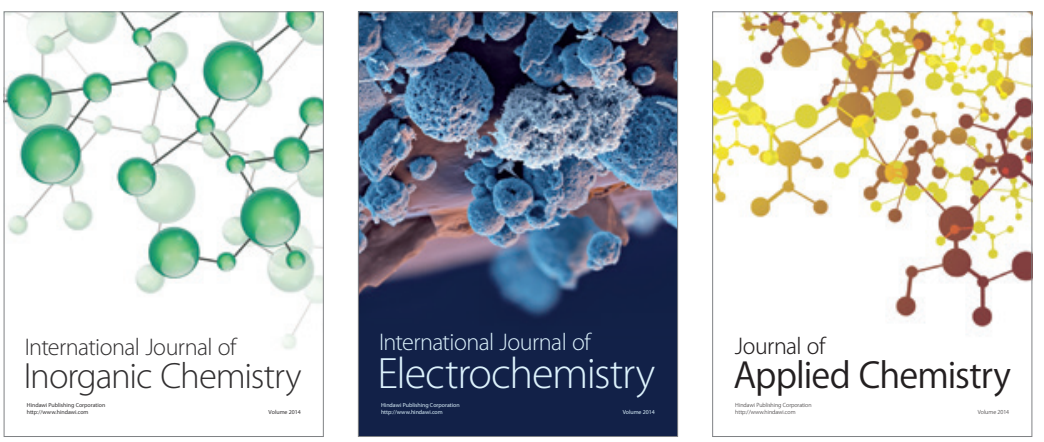

Journal of

Applied Chemistry
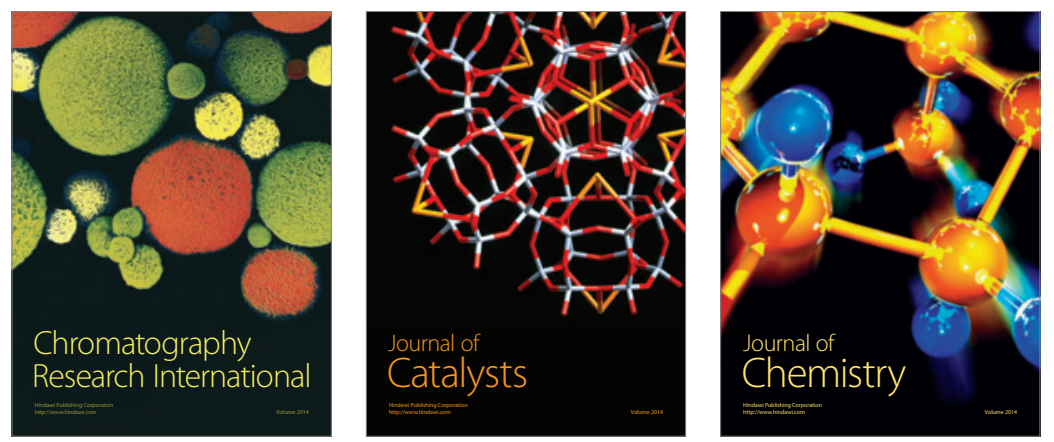
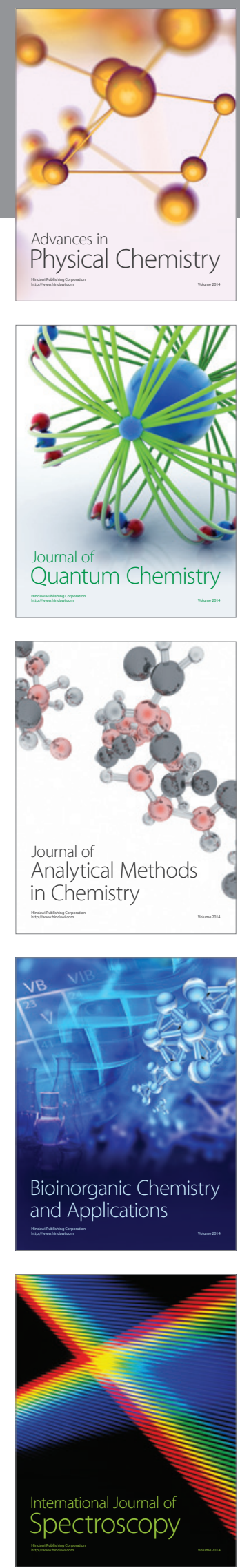